\author{
SAND90-1544 \\ Unlimited Release \\ Printed June, 1990

\section{Mode-Stirred Chamber Measurements of the Shielding Effectiveness of select Cables and Connectors} \\ Richard P. Toth and Larry D. Bacon \\ Microwave Physics Division \\ Sandia National Laboratories \\ Albuquerque, NM 87185
}

\title{
ABSTRACT
}

We have determined experimentally the Shielding Effectiveness (SE) at microwave frequencies nf various types of single- and double-braided cables and connectors typical of systems that have been hardened to electromagnetic fields. This report describes a laboratory-sized reverberation chamber and the techniques used to measure the $\mathrm{SE}$ of several interconnectirg components. Graphical results are presented in the report, along with smoothed overlay plots for each category of measurements. The overlay plots indicate the general trends in the raw data and highlight the differences between tested components. 


\section{TABLE OF CONTENTS}

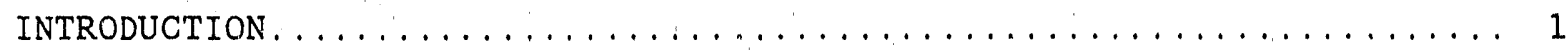

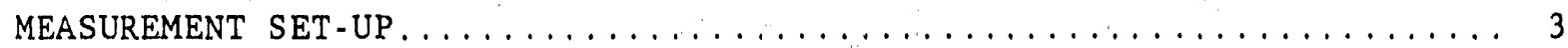

Mode-stirred chamber........................... 3

Mode stirrer............................... 3

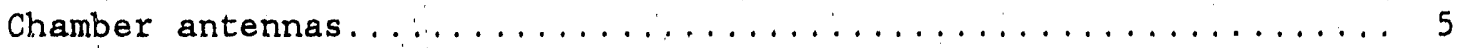

Experiment insertion panels..................... 7

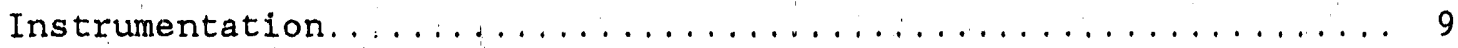

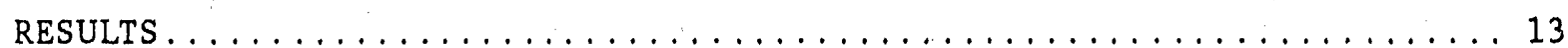

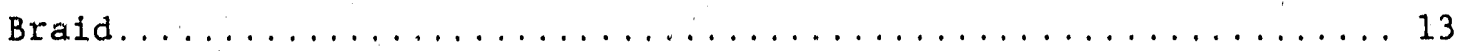

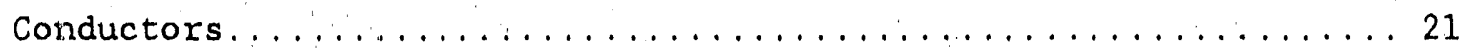

Cables.................................... 25

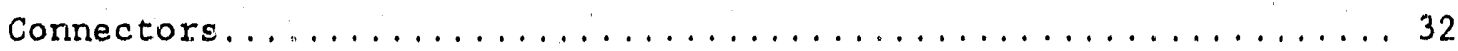

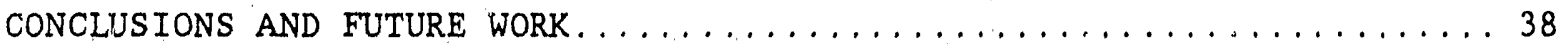

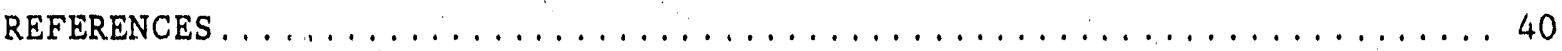

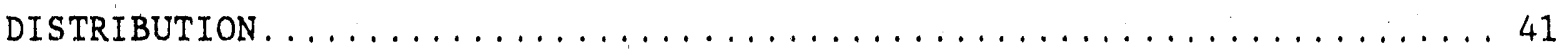




\section{LIST OF FIGURES}

Page

Figure 1. $\quad$ Mode-stirred chamber................... 4

Figure 2. Interior view of mode-stirred chamber $\ldots \ldots \ldots \ldots \ldots$

Figure 3. Connector insertion panel................ 8

Figure $4 . \quad$ Cable insertion panel...................... 10

Figure 5. Diagram of the instrumentation................

Figure $6 . \quad$ Shield braid repeatability runs $\ldots \ldots \ldots \ldots \ldots \ldots \ldots \ldots$

Figure 7. Shielding effectiveness of RG -220 braid.......... 16

Figure $8 . \quad$ Shielding effectiveness of Flat braid............ 17

Figure 9. Shielding effectiveness of Unknown braid .......... 18

Figure 10. Composite of braid shielding effectiveness........... 20

Figure 11. Shielding effectiveness of ungrounded wire bundle.....22

Figure 12. Shielding effectiveness of grounded wire bundle......223

Figure 13. Composite of wire bundle shielding effectiveness...... 24

Figure 14. Shielding effectiveness of RG-58/U cable..........26

Figure 15. Shielding effectiveness of $R G-223 / U$ cable.......... 27

Figure 16. Shielding effectiveness of Astrolab 16301 cable...... 29

Figure 17. Shielding effectiveness of Adams-Russell cable....... 30

Figure 18. Composite of cable shielding effectiveness.......... 31

Figure 19. Shielding effectiveness of EMP-hardened connector pair.. 33

Figure 20. : Shielding effectiveness of non-hardened connector pair.. 34

Figure 21. Shielding effectiveness of lightning-protected

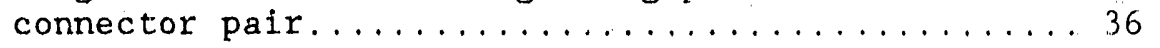

Figure 22. Composite of connector shielding effectiveness....... 37 
INTRODUCTION

This report presents the results of an experimental investigation of the leakage of microwave currents on the exterior of typical interconnecting components onto the internal conductors. A measure of this leakage is the shielding effectiveness, which is the ratio in decibels ( $d B$ ) of the power received by a shielded load to the power that would be received by the load ir the absence of the shield [1]. To minimize the harmful effects of coupled electromagnetic energy on electronic systems and components, the shielding effectiveness (SE) of interconnecting devices should be as large as possible, given the restraints of physical size, weight, and cost of the system under investigation. In practice, the measurement of shielding effectiveness of electronic interconnecting devices requires the exposure of the components to reproducible electromagnetic fields over a wide range of frequencies.

Two methods currently used to establish these reproducible electromagnetic fields in a laboratory environment are the Transverse Electromagnetic cell (TEM cell) and the Mode-Stirred Chamber (MSC). The TEM cell is basically a section of rectangular transmission line with tapared sections on both ends. It maintains a fixed polarization between the applied field and the component under test, but suffers from having a limited test volume and upper frequency range. The analysis of data obtained 
with it must be carefully interpreted if meaningful comparisons with other measurement methods is attempted. The reader is referred to an excellent review article [2] for an extensive discussion on the operating characteristics of TEM cells:

The limitations on the upper operating frequency range of the TEM cell can be overcome by use of a class of test volumes known as reverberation chambers. Reverberation chambers are essentially overmoded resonant cavities which possess a means of altering the mode configuration within the test volume. Depending on the purpose of such chambers, they have been called Mode-Tuned Chambers, Mode-Spoiled Chambers, and Mode-Stirred Chambers. The chambers are capable of establishing, in an averaged sense, a homogeneous and isotropic electromagnetic field within the test volume. The polaxization is not fixed, but continuously varied by means of a rotating paddle called a mode-stirrer or mode-tuner. Operating frequencies can cover a few hundred megahertz up to several gigahertz, depending on the chamber size. The principal drawback to its use is the large chamber size required at low operating frequencies. The reader is again directed to reference [2] for an in-depth evaluation of reverberating chamber characteristics.

The following sections describe the design and construction of a laboratory-sized mode-stirred chamber, and the interconnecting hardware and procedures for measuring the shielding effectiveness of cable braids, wire bundles, coaxial cables, and multi-pin connectors. 
MEASUREMENT SET-UP

Mode-stirred chamber. A laboratory size mode-stirred chamber was constructed by modifying a standard electronic rack (figure 1). The external cabinet dimensions were 74 -inches high by 31 -inches deep by 22 inches wide. Based on a ninimum number of ten modes present in the chamber, these dimensions indicated a lower usable frequency of approximately 200 $\mathrm{MHz}$. The cabinet was stripped down to the basic framing structure in which top and bottom, and both left and right cover panels remained intact. All seams were sealed with 2 -inch wide copper shield tape on both inner and outer surfaces, to establish chamber integrity. The equipment mounting rails were re-installed in the front and rear openings. A 1 -inch wide strip of flat mesh RF gasket material was fixed in place over the mounting hole rails and the entire front and back opening was covered with blank cover panels copper taped in place, to the mounting rails. Machine screws were installed in the blank panel openings over the the top of the copper tape. Seams between adjacent panels were also taped. A single 7-inch high panel opening in the center of the front section was retained for experiment access. The final internal dimensions of the chamber were 73-inches high by 29-inches deep by 22 -inches wide. Calculations using these dimensions indicated a minimum density of at least 10 modes could be supported down to a lower frequency of $350 \mathrm{MHz}$.

Mode stirrer. A stepping solenoid with 15-degree step per increment was installed externally in the center of the top cover plate. A 1/4-inch 


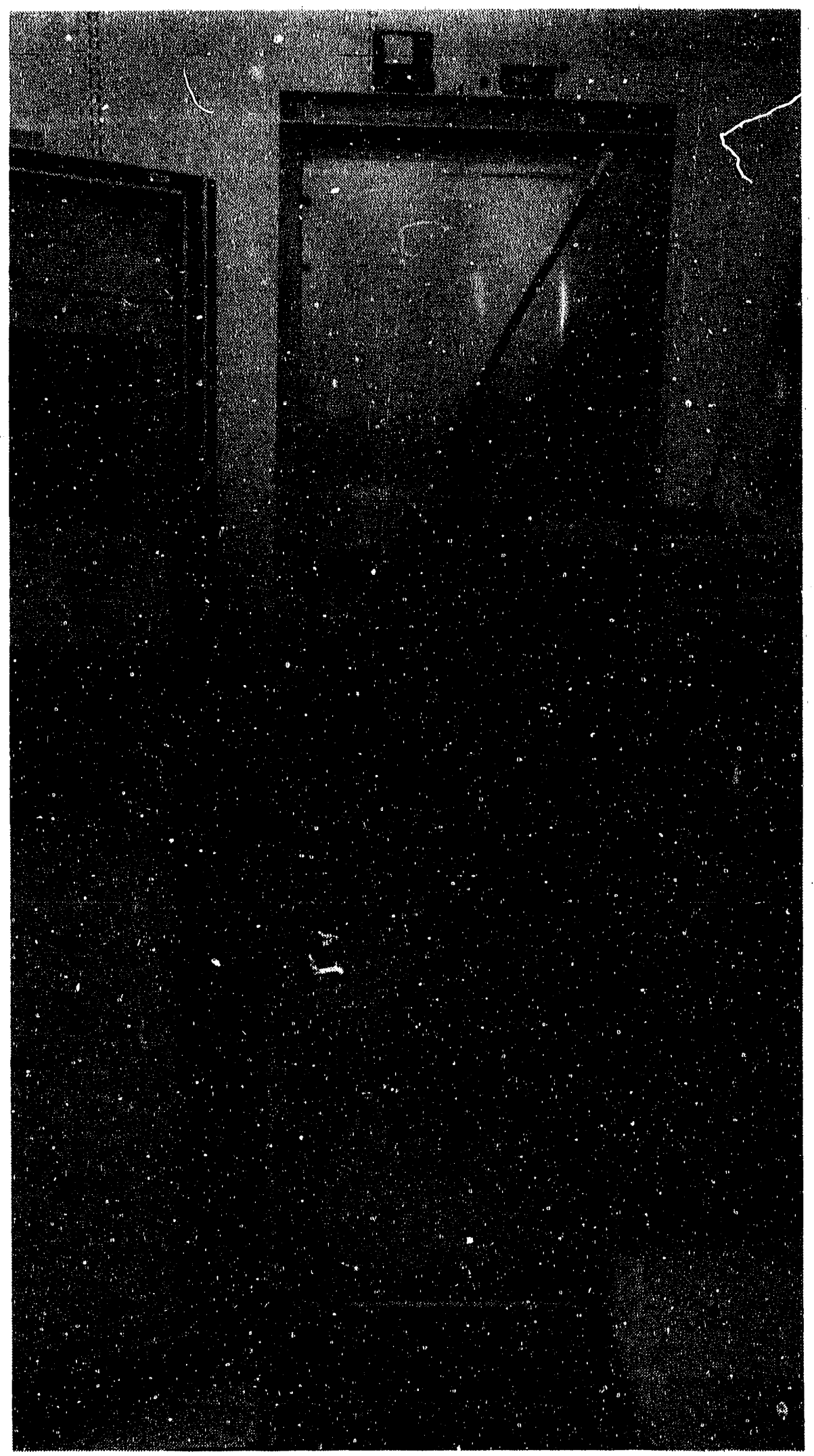

Figure 1. Mode-stirred chamber 
diameter dielectric shaft penetrated the top plate and extended approximately 24 -inches downward to the center of the experimental volume. A mode-stirring paddle based upon design guidelines of MIL-STD-1344A [1] was fabricated and affixed to the shaft (figure 2). Electrical actuation of the solenoid produced a 15 -degree rotation of the stirring paddle for each individual actuation.

Chamber antennas. Two identical antennas were installed in the chamber to provide RF excitation to the chamber interior and experimental componencs, A Vee and inverted-Vee structure (figure 2) was used in the chamier to avoid inductive coupling between antennas, which would occur if the antenna elements were positioned paralle] to each other [3]. The right side of the chamber contained a type- $\mathrm{N}$ bulithead feedthrough connector on the upper front and rear panel covers. The antenna was constructed from \#12 AWG insulated solid copper wire which extended from the upper front feedthrough, down to the center bottom of the right side panel, and up to the rear panel feedthrough. If seen through the right side panel, the antenna element would form a true Vee figure. The left side antenna is simjlar, but inverted to form an inverted-Vee shape with the corresponding bulkhead feedthroughs on the lower front and rear cover panels. The antenna wires are held approximately 3 -inches from the side panels with small pieces of PVC tubing acting as standoff insulators. 50-Ohm terminators are installed on the rear type- $\mathrm{N}$ feedthrough connectors to terminate both antennas. 


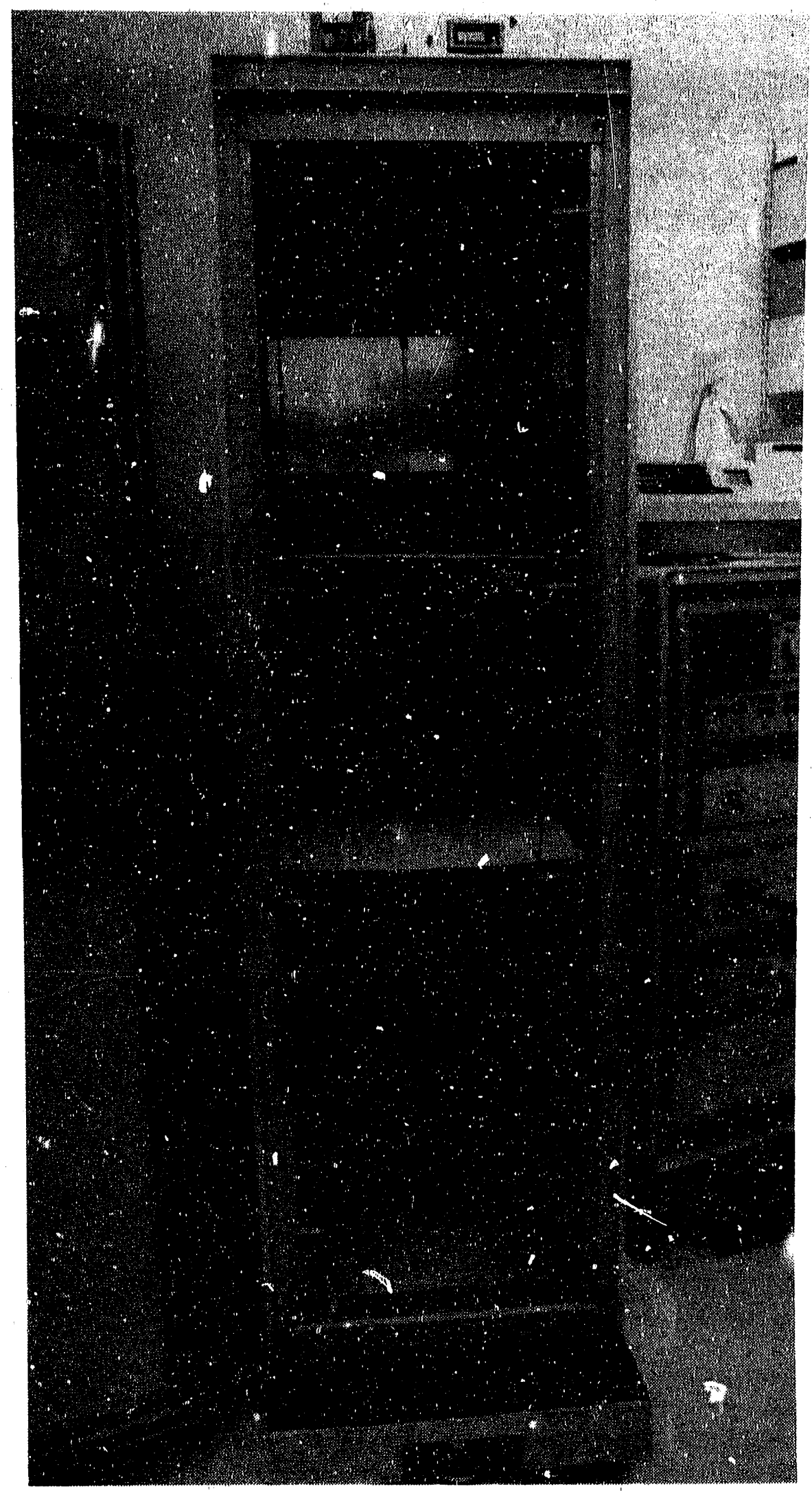

Figure 2. Interior view of mode-stirred chamber 
Experiment insertion pane1s. Two experiment insertion panels were fabricated to facilitate the insertion of either cables or connector assemblies into the center section of the mode-stirred chamber. The pane1s were designed to maintain complete shielding integrity from the panel inward to the actual connector or cable under test.

This was dorie for the connector insertion panel (figure 3) by use of short lengths of Breeze tubing and adaptors [4]. Breeze tubing is made of thin-gage brass tubing which is cylindrically expanded to a corrugated shape for flexibility. The longitudinal seam is completely welded to provide total seam closure, and the tubing protected against abrasion by enclosure in a double-braided copper armour sheath. Ferrules and gland nuts are soldered on the ends of the tubing to facilitate attachment to feed-through adaptors. The panel contained two type- $\mathrm{N}$ bulkhead feedthrough connectors separated by 12-inches, each of which affixed the body of a 3-inch X 4-inch aluminum minibox $t$ the inner face of the panel. The Breeze tubing feedthrough was positioned in the center of the minibox cover. With the cover fastened to the minibox body and seams copper taped, the shield is essentially extended intact from the front of the insertion panel inward to the connector adaptor. Connectors to be tested in the mode-stirred chamber were attached to the free ends of the breeze tubing with standard threaded glands and fittings. A single male-female connecting pair was chosen for the shielding-effectiveness measurements, The mated-pair connection was brought out to the panel. feedthroughs by short lengths of RG-58/U soldered to each element of the pair. A BNC-to-N adaptor installed in the minibox completed the connection to the front panel. In actual useage, one side of the connector pair was terminated in 50 Ohms by means of a terminator 


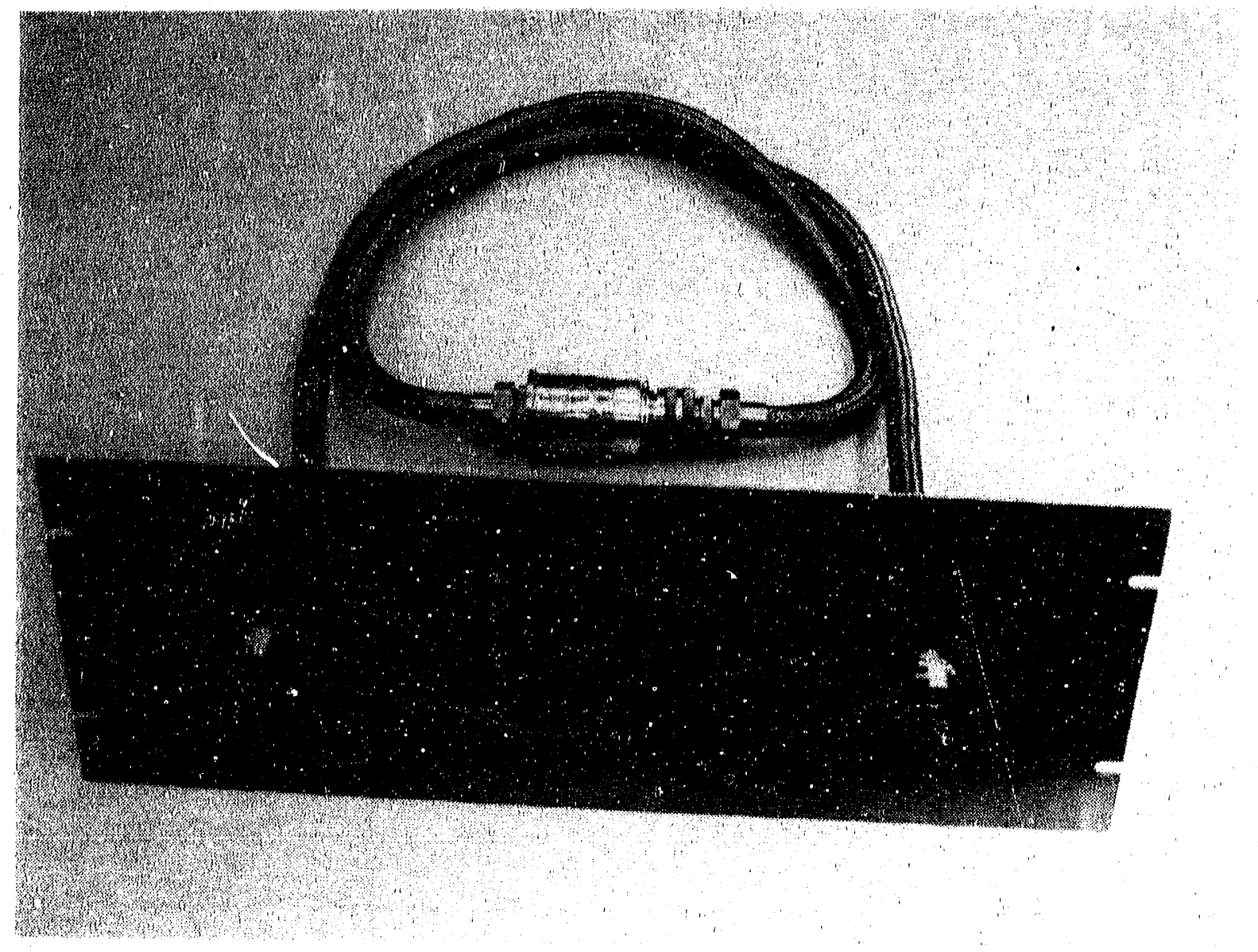

Figure 3. Connector insertion panel 
affixed to one of the front panel feedthiough connectors.

In the case of the cable insertion panel (figure 4), a different concept had to be invoked. In order to maintain shielding integrity from the front panel inward, the entire outer shield was made of $3 / 4$-inch copper tubing and solder fittings formed as two L-shaped sections. The outer diameter of the copper tubing was held in place with large friction fittings which allowed insertion depth adjustment if needed. The front panel ends of the tubes were closed off with soldered caps into which $1 / 4$-inch diameter, semi-rigid coaxial cables were positioned and fixed with smaller diameter friction fittings. Panel ends of the semi-rigid cables had SMA connectors installed. The opposite ends of the cable had approximately 6 -inches of copper sheath removed to allow bending through the rear L-section. Adjustment and tensioning after the test wires or cables were soldered was done by pulling on the semi-rigid cable from the front panel and then tightening the friction fittings to maintain the desired positioning.

Instrumentation. A Hewlett-Packard mode1 8510 vector network analyzer with a model $8515 \mathrm{~S}$-parameter test set was used to acquire experimental data from the mode-stirred chamber (figure 5). The system was configured to record the S21 scattering parameter over a frequency range of 1 to $11 \mathrm{GHz}$, for a total recording span of $10 \mathrm{GHz}$. The analyzer was operated in the stepped mode, using 801 frequency increments of $12.5 \mathrm{MHz} /$ step to transit the frequency endpoints. In anticipation of recording extremely low-leve1 signals, each frequency step was recorded and averaged 1024 times to improve the signal-to-noise ratio. The mode-stirring paddle remained in a fixed 


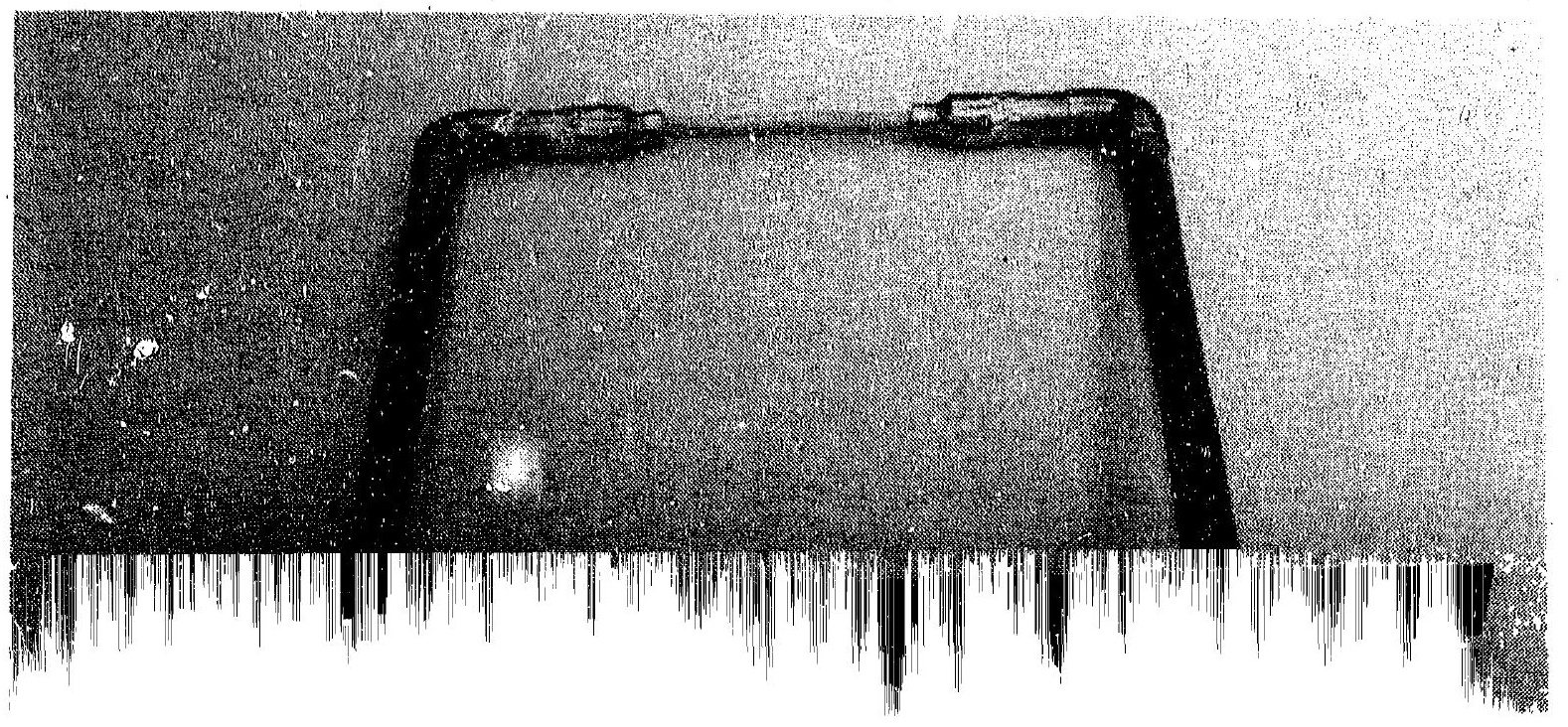




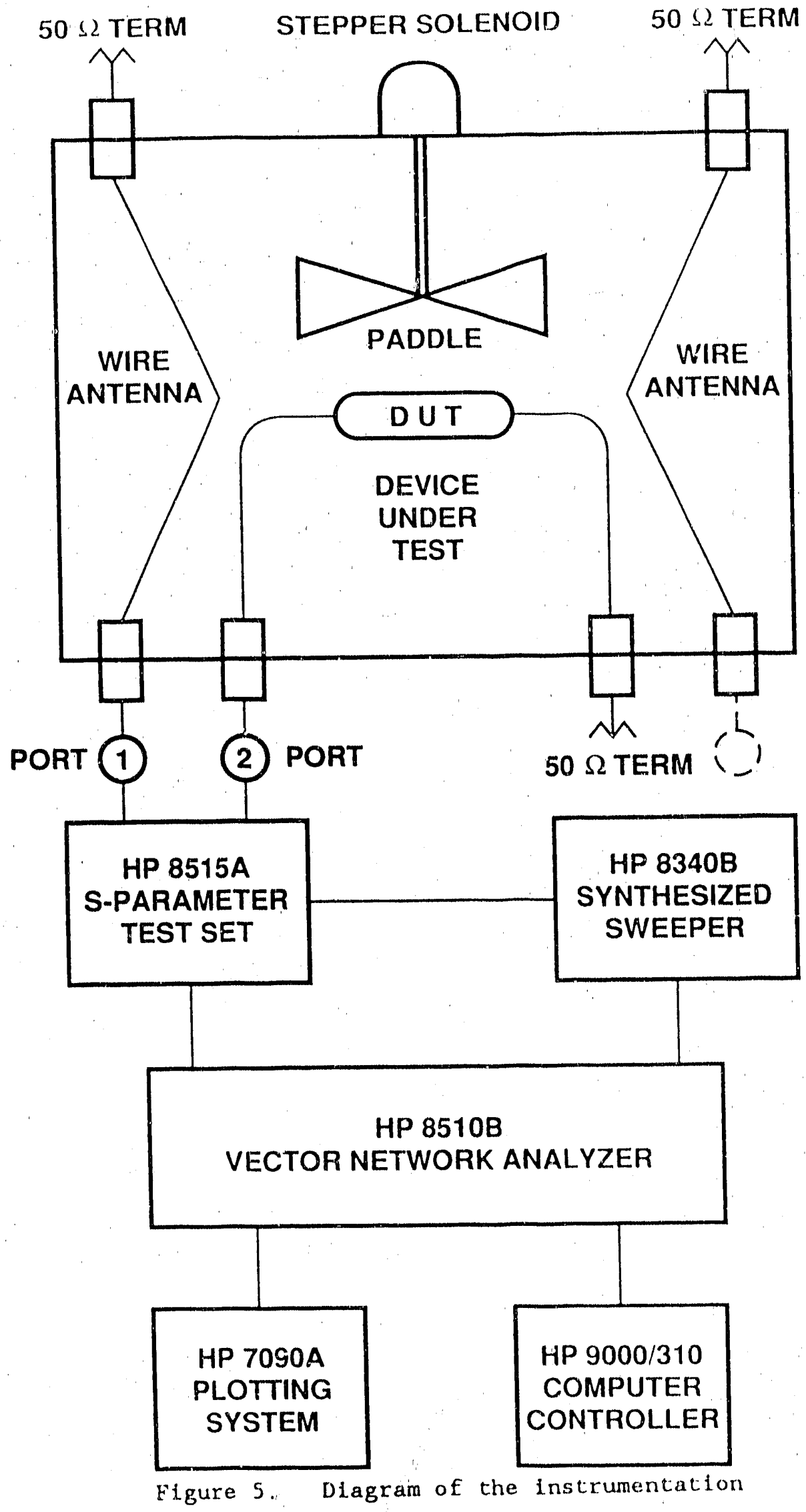


position during the data acquisition portion of the experiments. Since the purpose of the paddle is to perturb the boundary conditions of the chamber during measurement - - in essence, providing a mechanical averaging scheme - . using incremental frequency steps and averaging over frequency performs the same function, with results typically within 2 to $3 \mathrm{~dB}$ [5]. To validate this, a test was run on the bare chamber with the paddle stepped through an entire revolution in 30-degree increments, and a complete frequency scan was performed at each paddle position. The data traces were overlay-plotted to reveal any obvious changes caused by the paddle position. The results of the paddle position test showed that there was only a minor shifting of resonance peaks with paddle position. The baxe chamber measurements also indicated that there was a $-20 \mathrm{~dB}$ loss in the chamber between the transmit and receive antennas, with a deviation of $10 \mathrm{~dB}$ about the mean.

Once acquired, the data was sent to a plotter for notebook copies; then transferred to data files on the minicomputer used as a system controller. The data files were reformatted and transferred to the large VAX computer for additional processing and analysis using the SIG signal processing program. 
RESULTS

Data was acquired for two major categories of interconnecting devices: cables and connectors. The cable category was further subdivided by the separate investigation of the two principle constituents of coaxial cables: the shield (braid), and the inner conductors (wires). We begin by looking at the effects of shield braid, then conductors, then complete cable assemblies. The report concludes with an investigation of various classes of multi-pin connectors.

Braid. Initial measurements of the shielding effectiveness of shield braid showed systematic effects across the frequency spectrum which were independent of the braid under test. These effects were caused by resonances due to the lengths of copper pipe used on the cable insertion pane1. They were reduced by wrapping the pipes with a microwave absorbing "space-cloth" fabric [6]. The material presents the same $377-0 h m$ characteristic wave impedance as free space.

A series of measurements on a single braid were made to see if there remained systematic effects due to the way the specimens were installed and removed from the insertion panel. A section of braid from $R G-220 / U$ cable was repeatedly installed, measured, and removed from the test panel using the same method to be applied to all the braids. An overlay plot of the results, smoothed by a 25 -point moving average over frequency, (figure 6) indicated that the measurements were repeatable to within approximately 3 


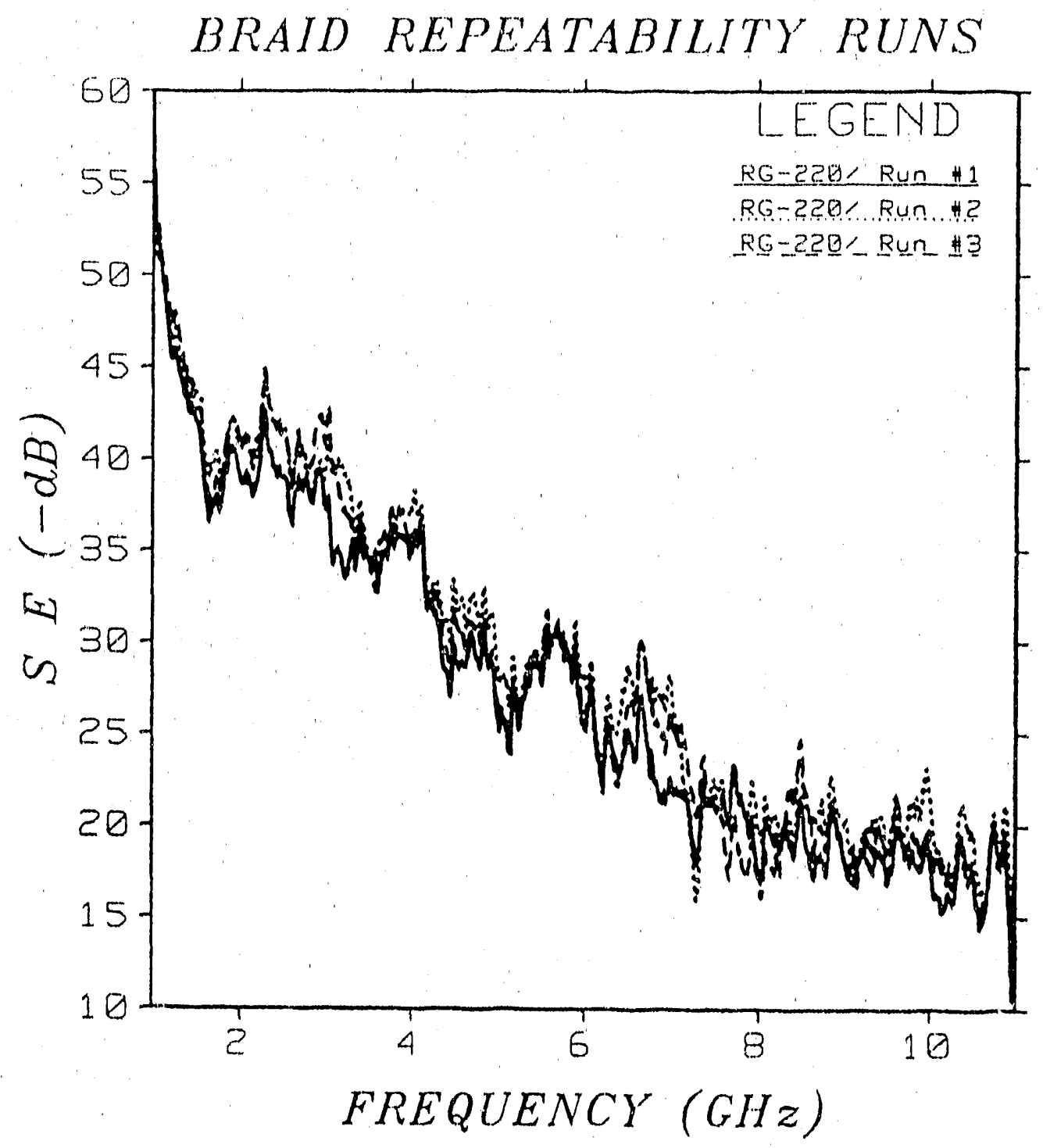

Figure 6. Shield braid repeatability runs 
$\mathrm{dB}$. The peaks in the plot at approximately 2 and $4 \mathrm{GHz}$ are thought to be length resonances caused by the $15-\mathrm{cm}$ coaxial receiving wire. The resonance seen at $6 \mathrm{GHz}$ is believed to be caused by the $5-\mathrm{cm}$ length of copper pipe joining the elbow transition. The short stub of pipe was left uncovered to facilitate insertion and removal of the braids.

A series of measurements was made on three different types of braided/woven shielding. The contribution of the braid construction to the overall shielding effectiveness is shown on the plots labeled DS356, DS354, and DS355 (figures 7, 8, and 9), respectively. Each section of braid was a 6-inch long cylinder and was approximately $3 / 4$-inch in diameter when installed on the cable insertion panel. A single insulated wire was located coaxially to the braided samples and became the receiving antenna for the SE measurement. The braiding geometries provided in the following paragraphs are "as-installed" figures, taken from each section of braid when mounted on the cable insertion panel. The numbers may be different from those given in the literature [7].

DS356- Figure 7 , is a section of shield braid removed from a piece of RG-220/U coaxial cable. Each strand of the shield is AWG \#22 bare copper wire, with 8 strands in each flat layup and a weaving geometry of approximately 5 picks/inch. The unfiltered plot shows a general decline in shielding effectiveness from $50 \mathrm{~dB}$ at $1 \mathrm{GHz}$ to $20 \mathrm{~dB}$ at $10 \mathrm{GHz}$, for a nominal frequency response of $-30 \mathrm{~dB}$ per decade.

DS354- Figure 8 , is a plece of 1-inch wide, flat grounding strap 


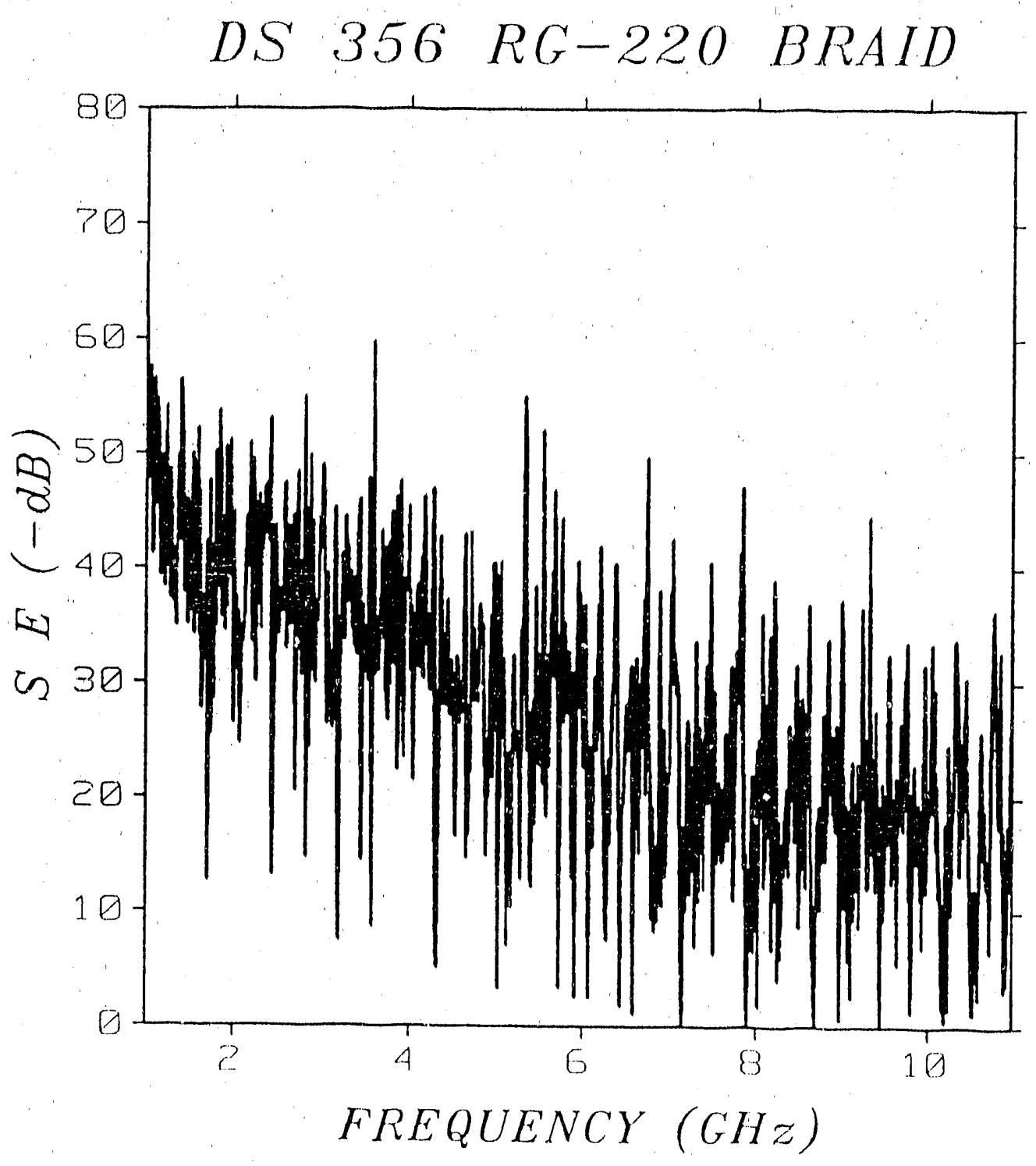

Figure 7. Shielding effectiveness of RG-220 braid 


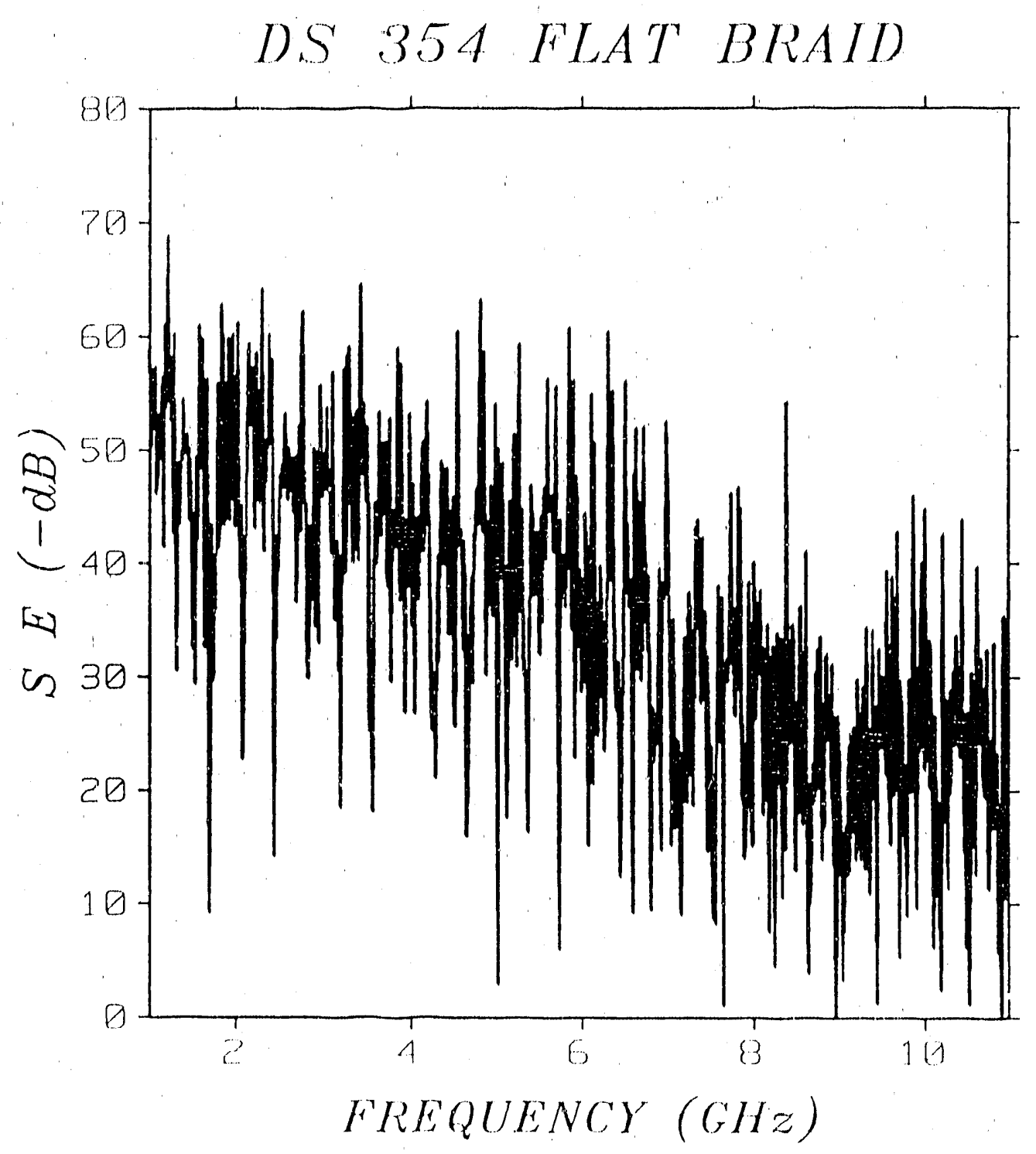

Figure 8. Shielding effectiveness of Flat braid 


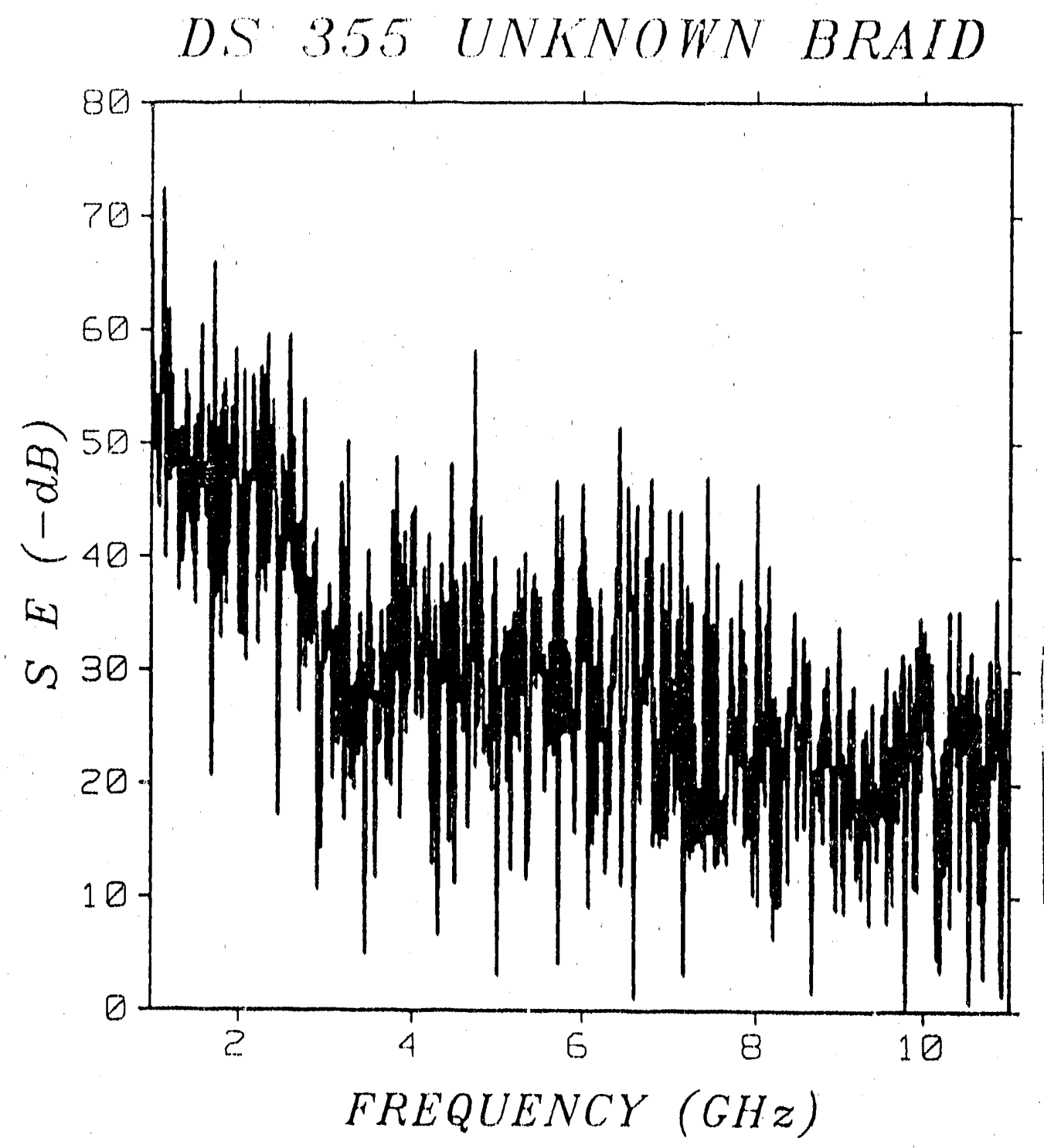

Figure 9. Shielding affectiveness of: Unknown braid 
which was reformed to a cylindrical geometry and irstalled on the cable insertion panel. This braid had individual strands of AWG \#28 tinned copper wire, with 11 strands in each layup and a weaving geometry of 10 plcks/1nch.

DS355- Figure 9, is a section of braid from an unknown source. The bratd has strands of AWG \#28 tinned copper wire with 11 strands per layup and a weaving geometry of approximately 6 picks/inch. The shield is belleved to be a section of brald from an RG-218/U coaxial cable. However, the true identity could not be verifled and so remains unknown for this report.

OVERLAY PLOT- Figure 10, has digital smoothing applied to each of the previous traces to reveal the similarities and differences between the various brald construction. Note the different behavior of the three specimens over the spectrum, especially the Improved performance of the flat strap braid over the unknown braid between 3 and $4 \mathrm{GHz}$. There is also an approximate $10 \mathrm{~dB}$ difference betweer the $R G-220$ and the flat strap braid. In general, it can be said that the tighter weaving geometry, 1.e., laiger number of plcks/inch, results in a somewhat larger value of shielding effectiveness for the cable. The trend is in the correct direction, since, in the limit, a tighter weaving geometry is approaching a solid shield construction. 


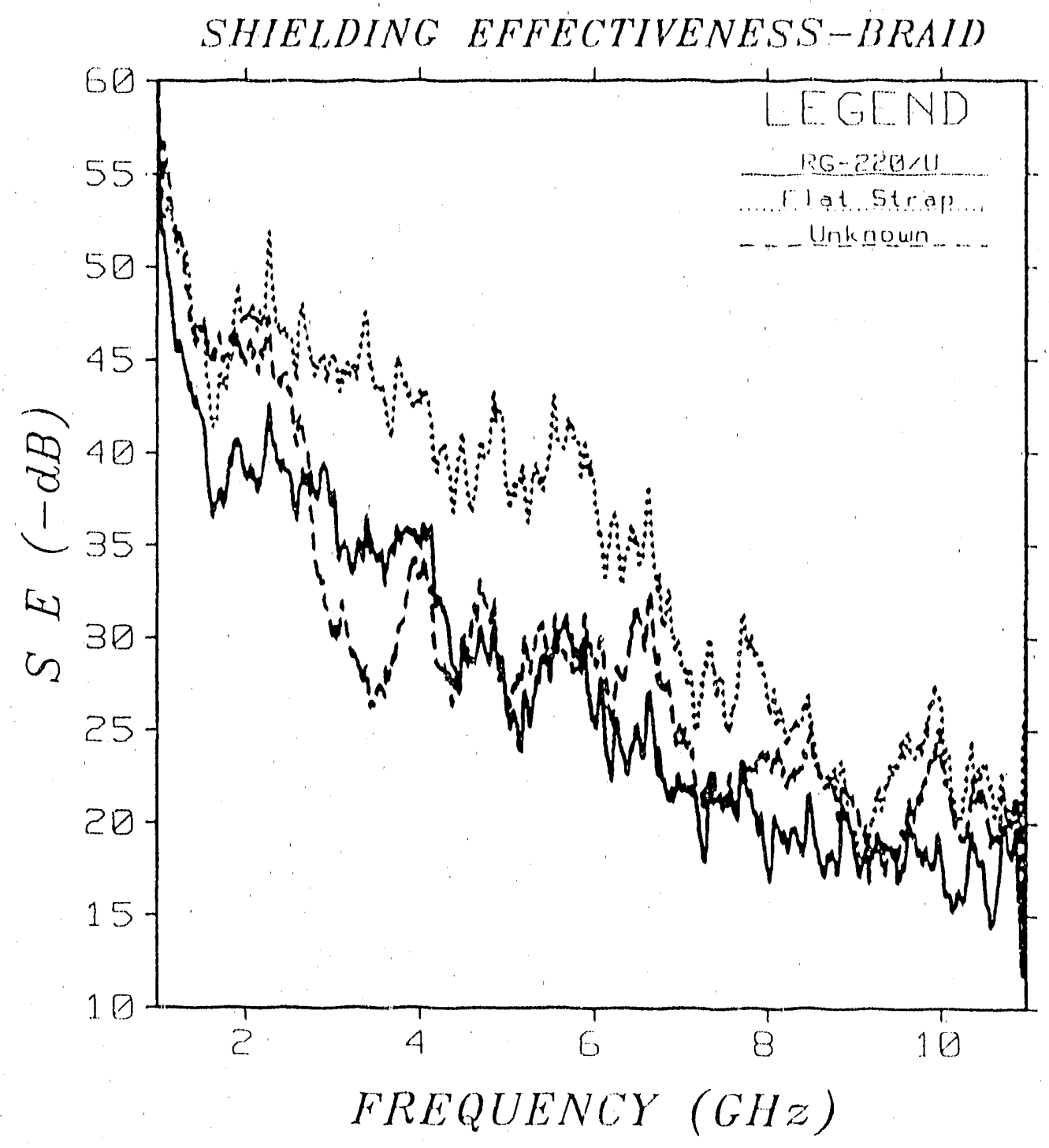

Figure 10. Composite of braid shielding effectiveness 
Conductors. A 6-inch, length of unshielded comnunications cable was Installed in the cable insertion panel to investigate the affects of surrounding conductors on the shielding effectiveness of a bundle of wires surrounding a single wire. The cable contalned 50 individually insulated, solid wire conductors with no intentional shielding. A centrally located wire was selected for the test, and measurements were made with the surrounding conductors ungrounded (floating) and grounded (connected to the insertion panel shield). Plots labeled DS332 and DS334 (figures 11 and 12), show the results of the measurements.

DS332- Tigure 11, shows the results of the SE measurement on the ungrounded bundle. Note the very low level of $\mathrm{SE}$, approximately 3 to $5 \mathrm{~dB}$, and the large fluctuation of $\mathrm{SE}$ above the mean level.

DS334-Figure 12, shows the slight improvement in SE when the surrounding wire bundle is grounded. It looks as if the limproved SE has been obtaired at the expense of larger than expected variability in the overall response. The small improvement in SE should not be too surprising since, in essence, the burled configuration is merely a preliminary version of a shield braid with an indeterininate wedving geometry.

OVERLAY PLOT- Figure 13, is again a smoothed version of the previous two figures. The smoothed overlay plot of each of the above traces indicates an approxlmate 5 to $1.0 \mathrm{~dB}$ improvement in the shielding effectiveness when the surrounding conductors have been grounded. The silght increase in SE seems to exhibit higher 


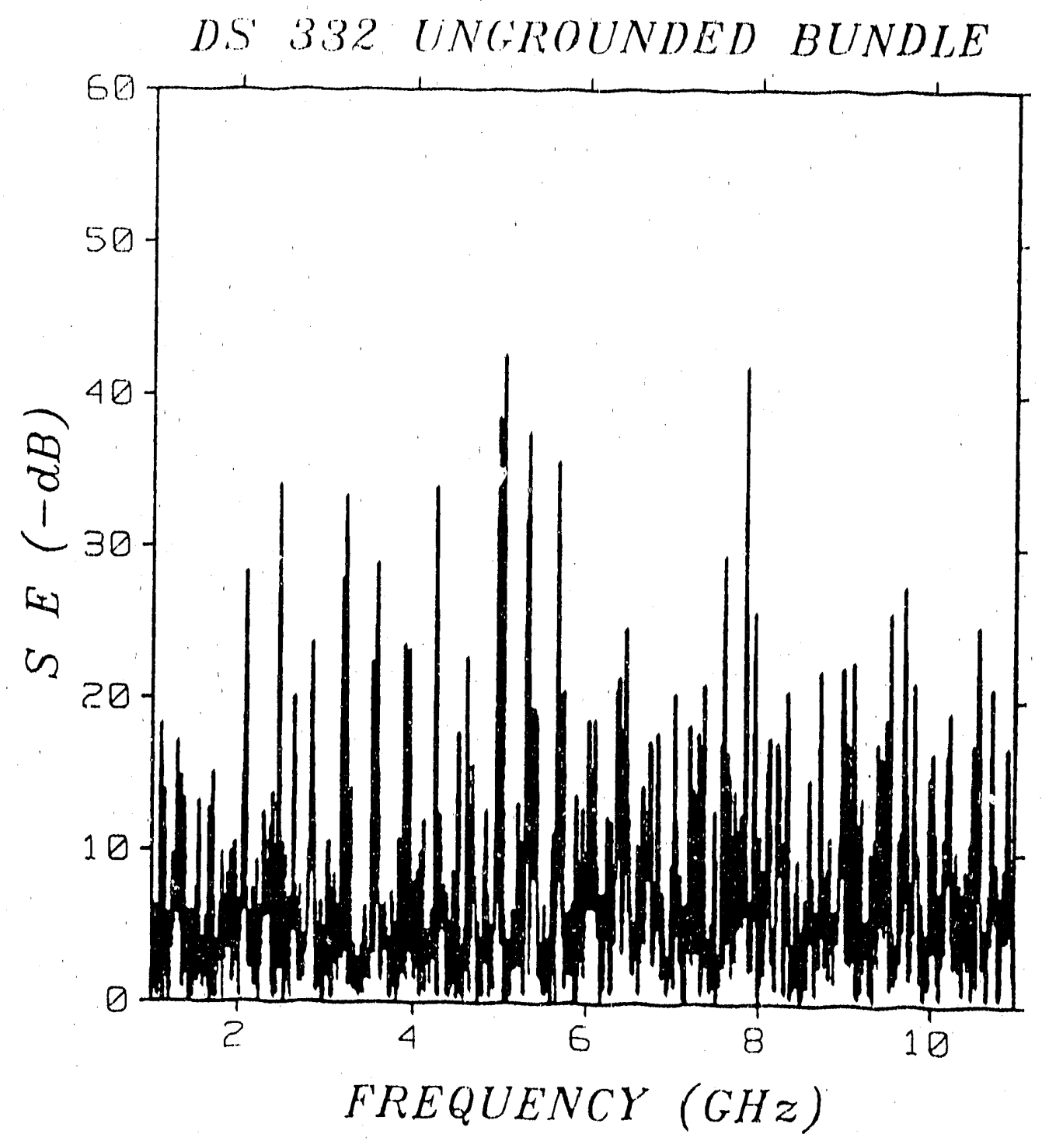

Figure 11. Shielding effectiveness of ungrounded wire bundle 


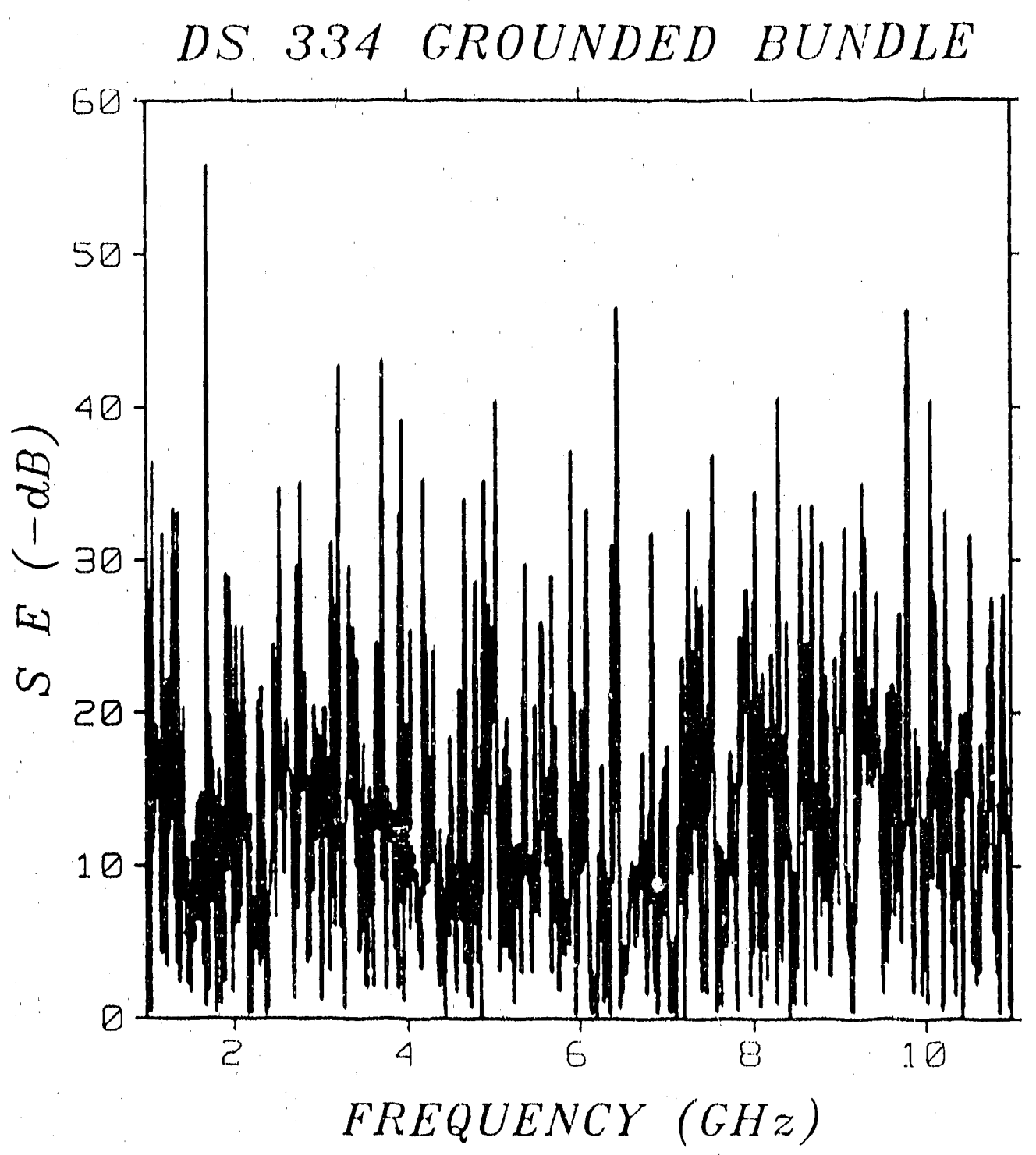

Figure 12. Shielding effectiveness of grounded wire bundle 


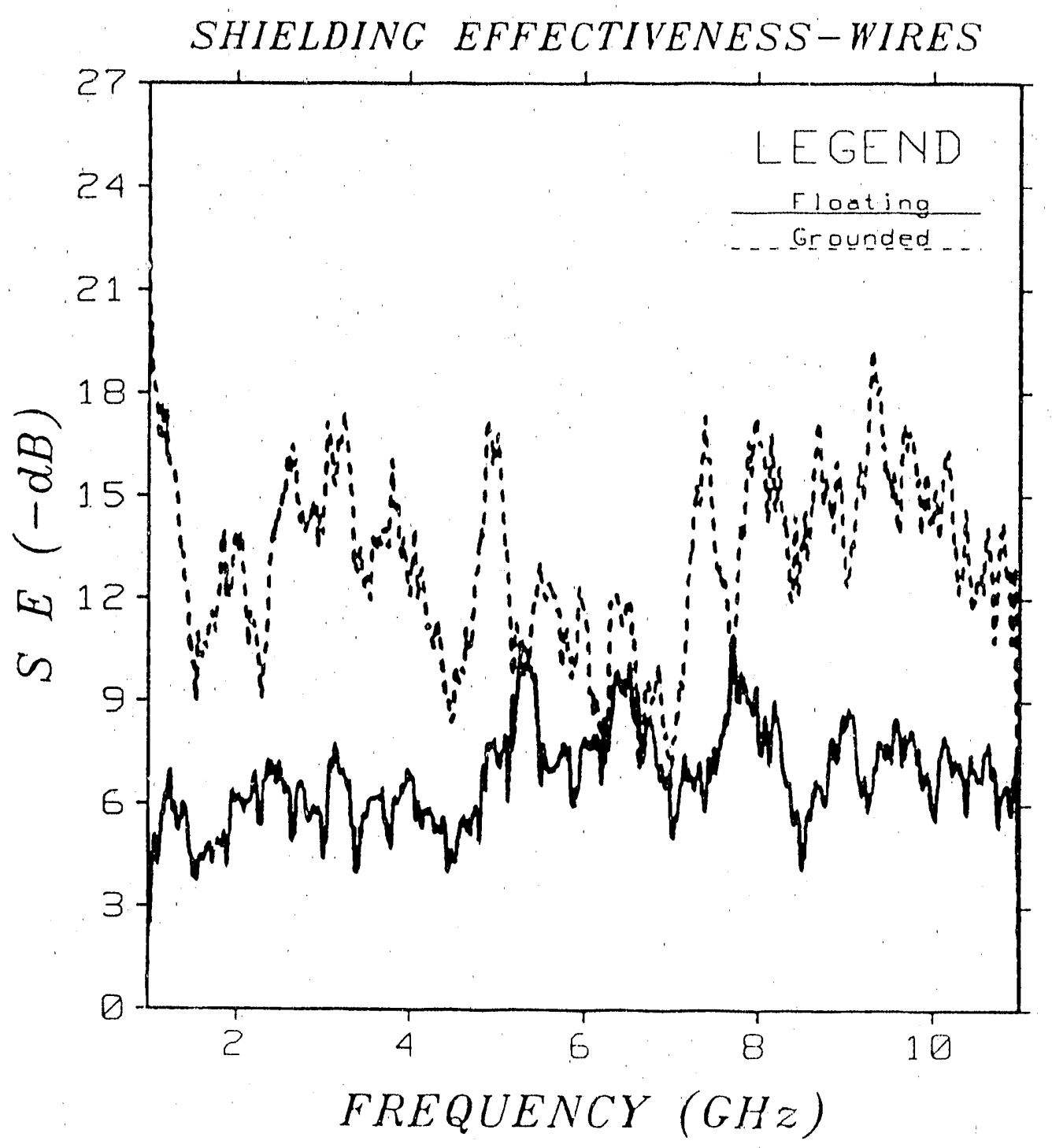

Figure 13. Composite of wire bundle shielding effectiveness 
deviation about the mean, perhaps indicating resonance effects between the center conductor and the surrounding wires in the cable bundle.

Cables. We conclude the investigation of braid and conductor influence on the shielding effectiveness of cables by performing measurements on complete cable assemblies with different shield braid construction. 1-meter lengths of cable vere installed in the connector insertion pane1 with the connector ends Locat $ə$ inside the panel shield boxes. The Breeze tubing was removed and each cable was configured with a single loop within the active volume of the mode-stirred chamber. Box seams and openings were sealed with copper tape.

DS313- Figure 14, shows the shielding effectiveness of common, single-braided RG-58/U coaxial cable. Use of a standardized weaving geometry for the braid is apparent from the reduction in fluctuation about the baseline. The baseline itself is seen to possess a definite structure with the expected -30 dB per decade response over the frequency range.

DS314-Figure 15, shows the shielding effectiveness of doublebraided RG-223/U coaxial cable. The effect due to the additional braiding layer is most pronounced. The overall response has improved to a $-20 \mathrm{~dB}$ per decade slope, an apparent $10 \mathrm{~dB}$ improvement over the single-braided cable. The baseline structure seen in the previous figure is absent, or, at least, suppressed. 


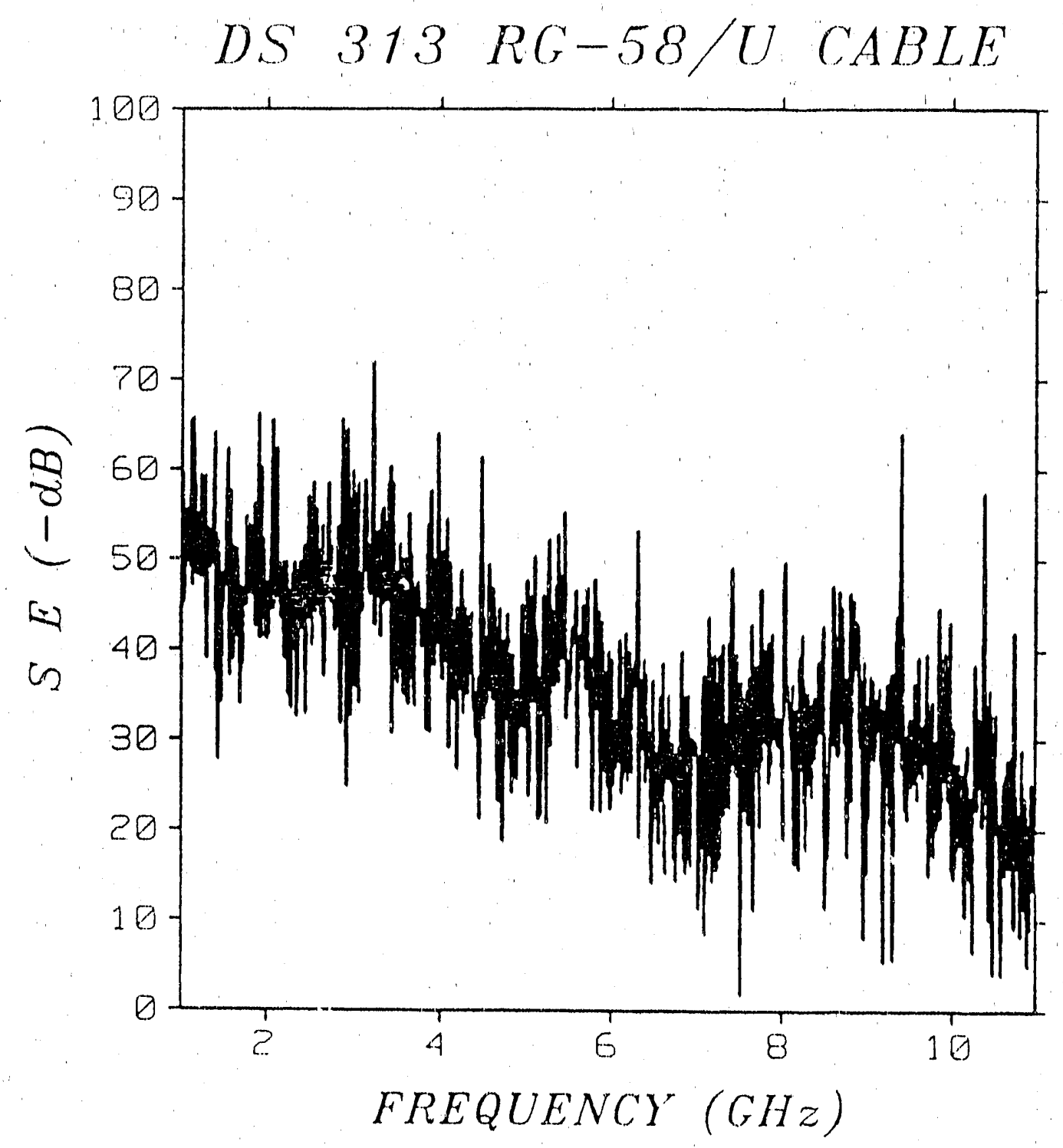

Figure 14. Shielding effectiveness of $R G-58 / \mathrm{N}$ cable 


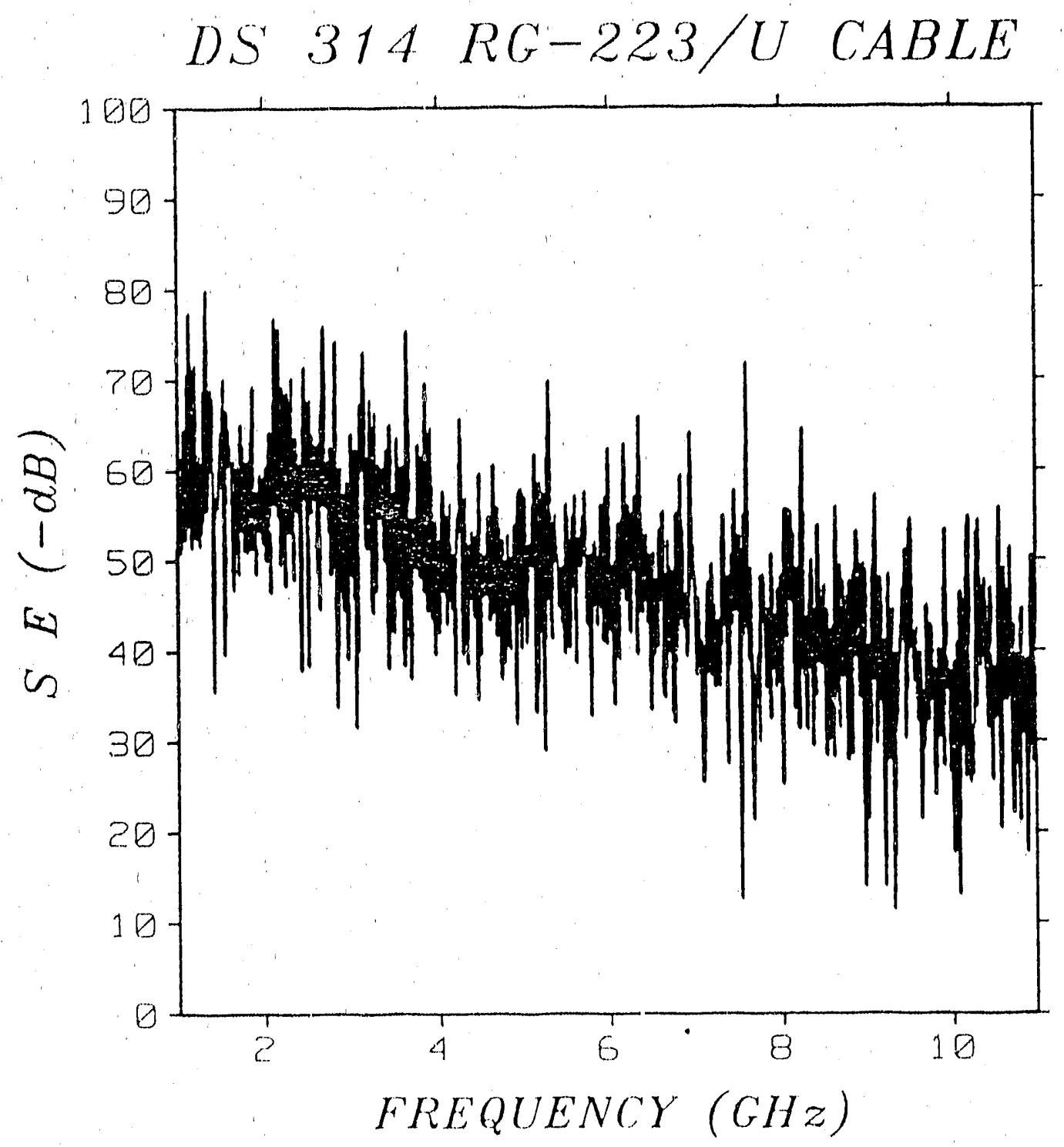

Figure 15. Shielding effectiveness of RG-223/U cable 
DS315- Figure 16, shows the shielding effectiveness of a laboratory-quality microwave coaxial cable. The 1 -meter long cable has a woven cloth outer protective covering and SMA connectors potted in a resilient compound. The internal construction is unknown at this time. The shielding effectiveness response is somewhat surprising in that the baseline is seen to possess a structure similar to that seen in the single-braided cable. It shows an enhanced SE at approximately $6 \mathrm{GHz}$, but then falls off at the higher frequencies.

DS316-Figure 17, is another 1 -meter long laboratory-quality microwave coaxial cable, similar to the prior unit, but from another manufacturer. It also has a cloth outer cover and potted SMA connectors. The internal construction is also unknown, but from the shielding effectiveness plot it seems to have double braid construction and a $-20 \mathrm{~dB}$ per octave response.

OVERLAY PLOT- Figure 18 is a smoothed version of all the above plots placed on the same axis to improve visual comparison. The relative differences between the different cables are readily apparent. The poorest performer is the single-braid RG-58/U cable. The double-braided RG-223/U and the suspected doublebraided Adams-Russe11 are seen to be quite similar in SE performance. The Astrolab cable seems to exhibits a SE somewhere between the single-braided and the double-braided responses. 


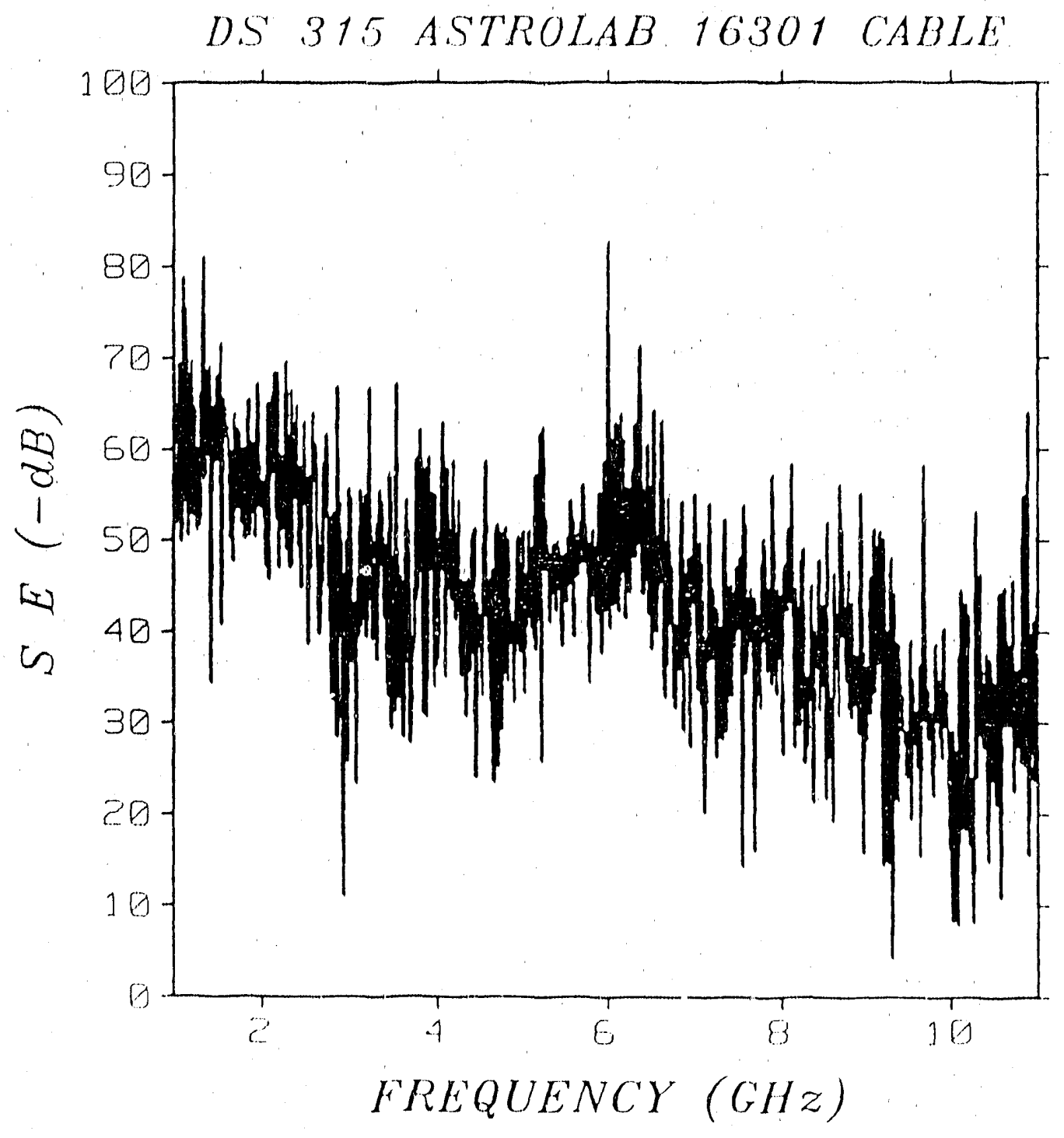

Figure 16. Shielding effectiveness of Astrolab 16301 cable 


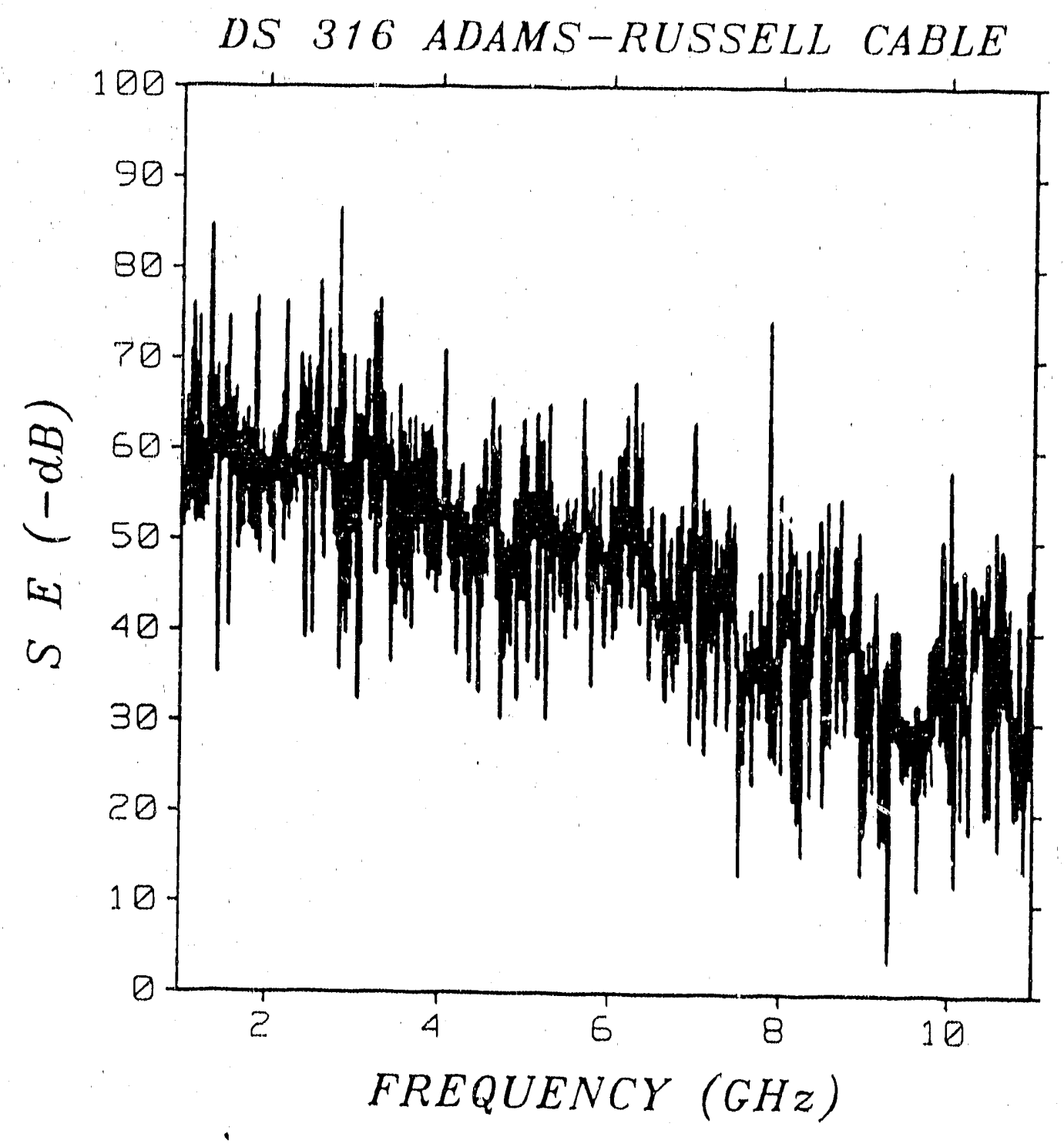

Figure 17. Shielding effectiveness of Adams-Russell cable 


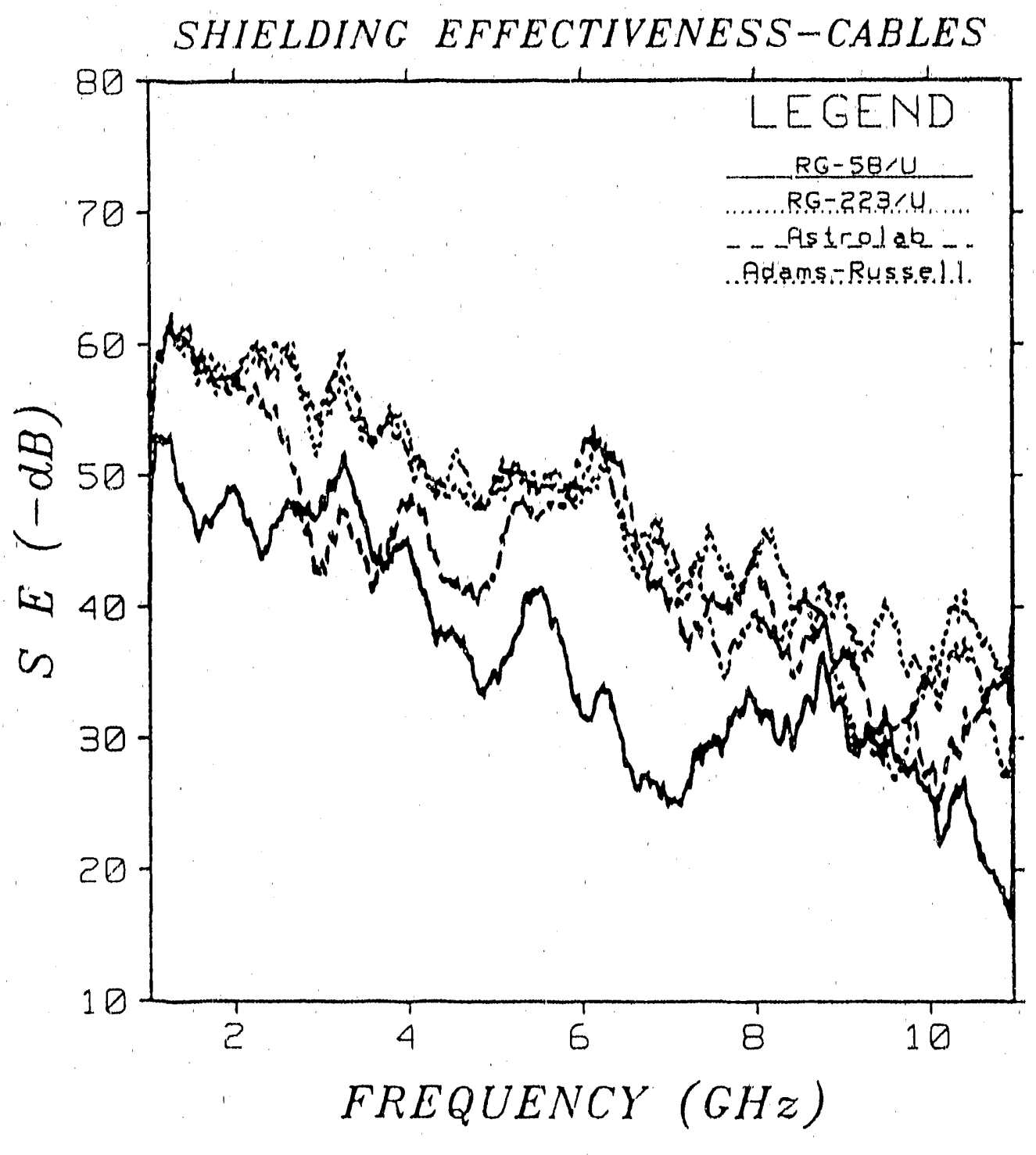

Figure 18. Composite of cable shielding effectiveness 
Connectors. The remaining element in our investigation concerns the shielding effectiveness of connectors, or rather, connector pairs. We were able to acquire identical mated pairs of multi-pin connectors in three styles: standard, EMP-hardened, and a lightning arresting version of the EMP-hardened untt. The standard pair came from the Bendix SA series of hermetically sealed, bayonet locking connectors. The EMP-hardened palr came from the WT series, also by Bendix. This version has conductive finger stock on the shell inner diameter which provides the EMP hardening feature. Upon assembly, the finger stock contacts the mating shell to provide an intact metal shield prior to actual pin and socket connection. The lightning arresting version of the above contains semiconducting thyrite material in intimate contact with the connecting pins. In the event of a lightning strike, or a large voltage being inadvertantly applied to the pins of the connector, the thyrite material will rapidly become conducting and thereby shunt the excess voltage to ground. The connector is somewhat larger than the EMP-hardened version to accomodate the added thyrite material and grounding sleeves.

DS322- Figure 19, shows the shielding effectiveness of the EMPhardened version of the connector. The baseline has a definite structure which is possibly due to resonance effects caused by the she11 circumferential dimensions and/or connector pin and socket lengths

DS323- Figure 20, shows the response of the standard version. Note the reduced level of SE, especially at the lower frequencies. 


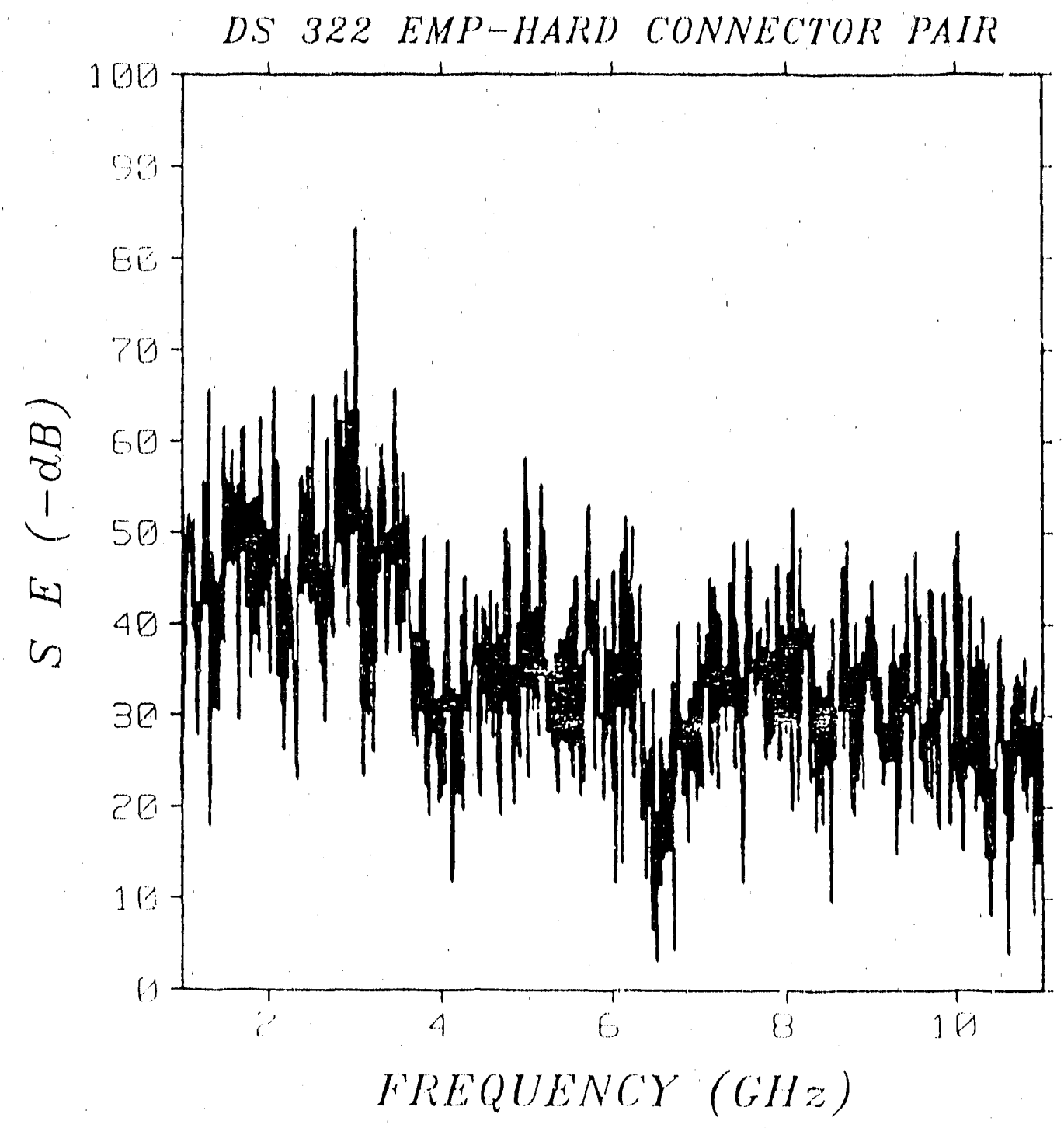

figure 1y. Shielding, effectiveness of EMp-hardened comocetos patr 


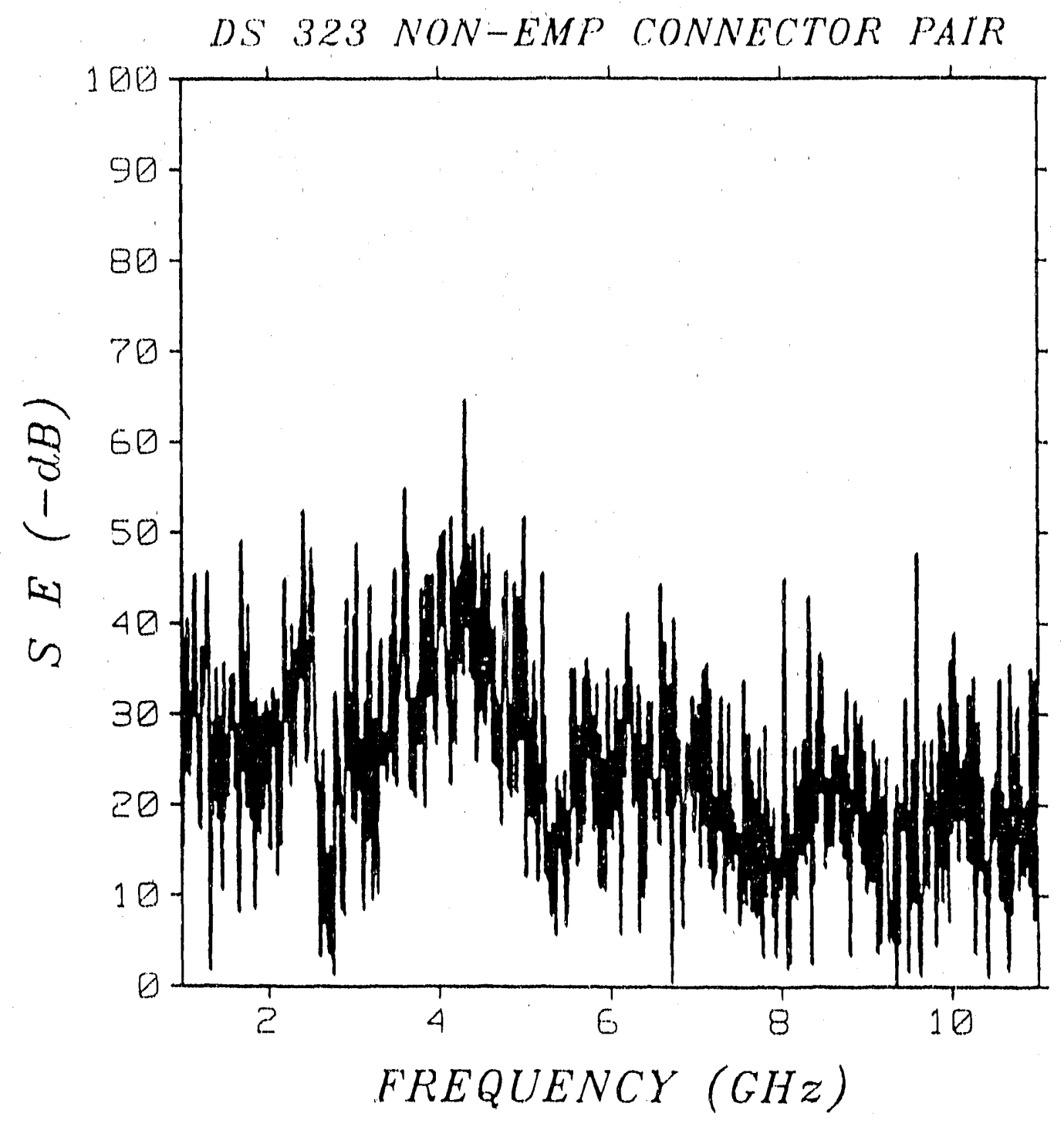

Figure 20. Shielding effectiveness of non-hardened connector pair 
A difference of $20 \mathrm{~dB}$ or more is seen between the EMP and non-EMP versions of the connector.

DS341. Figure 21, shows the response of the lightning protected connector to be very similiar to the EMP-hardened unit. structure is still seen in the baseline and the connector exhibits a trend with frequency of the SE of $-25 \mathrm{~dB}$ per decade.

OVERLAY PLOT-Figure 22, 11 lustrates the differences between the connector pairs. The EMP hardened connector is almost identical. to the lightning arresting version. Each show a pronounced dip in $\mathrm{SE}$ at $6 \mathrm{GHz}$, a possible resonance effect caused by the 1 -inch diameter mating shell and sleeve dimension of the connector. 


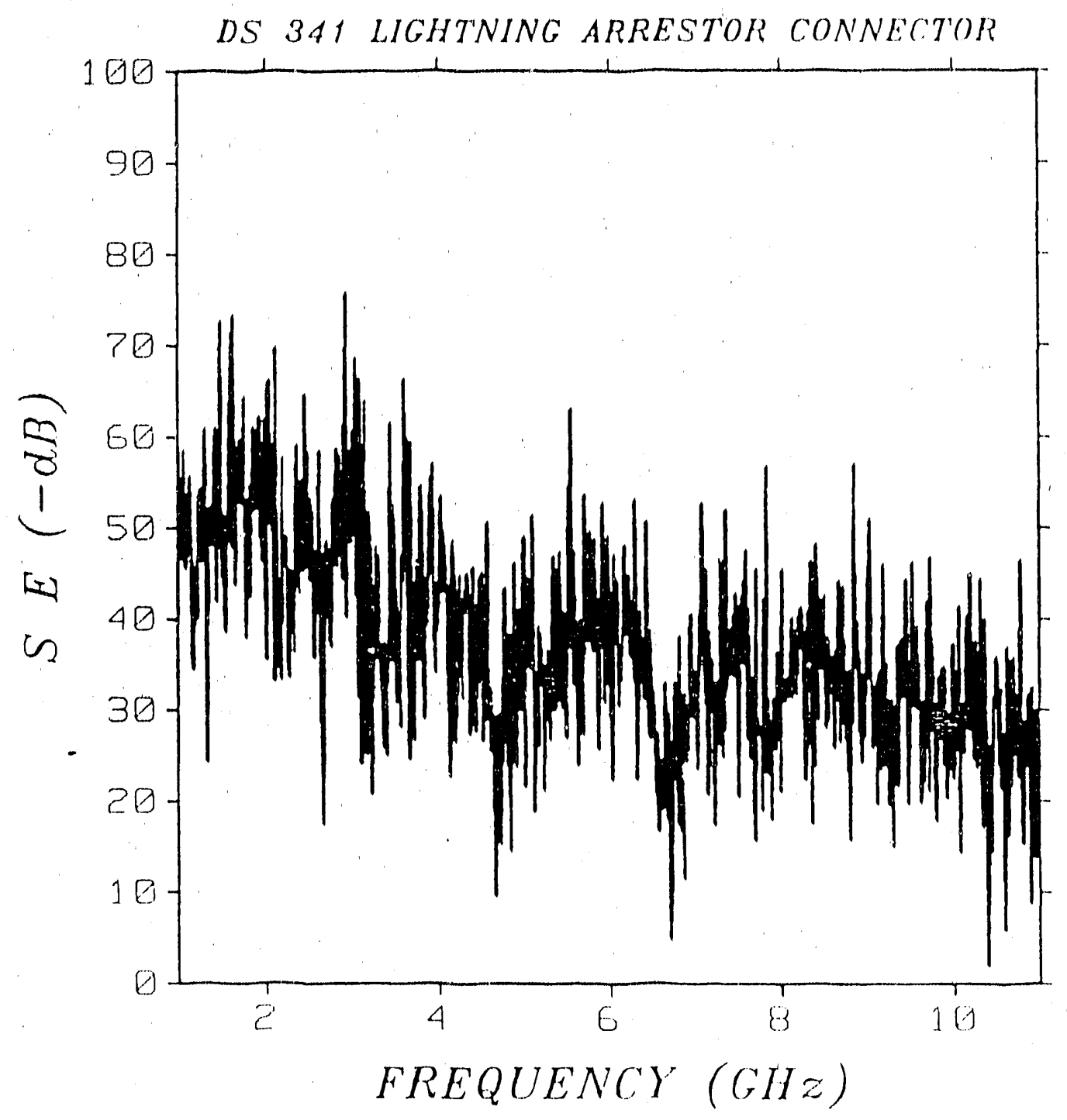

Figure 21. Shielding effectiveness of lightning-protected connector pair 


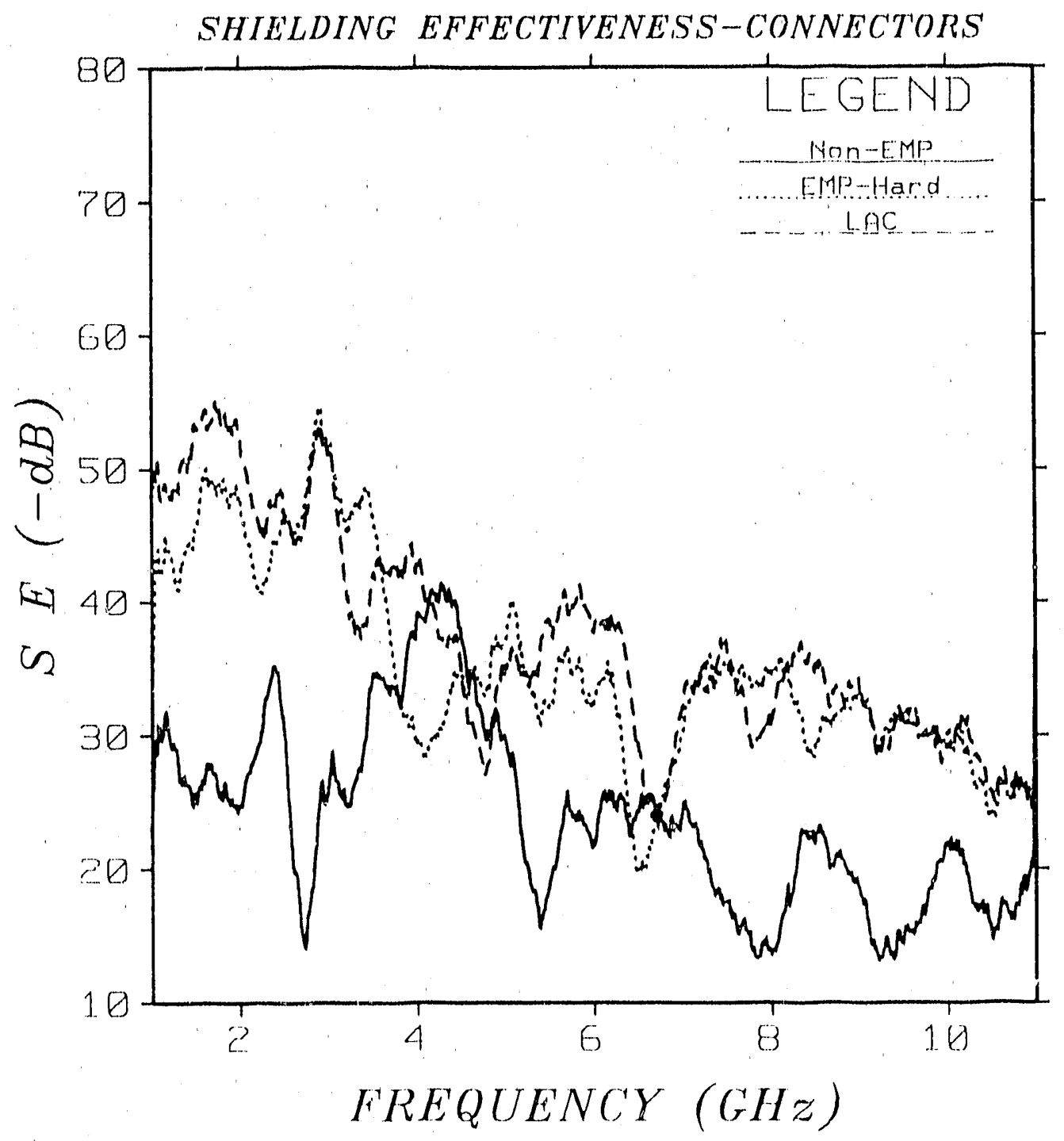

Figure 22. Composite of connector shideling effectiveness 
CONCLUSIONS AND FUTURE WORK

The results of the investigation described in this report are as follows:

1. There is a general decline in the shielding effectiveness with increasing frequency for all components tested.

2. A $6-12 \mathrm{~dB}$ shielding improvement is obtained from having conductors buried in the center of multi-conductor cables which are not shielded.

3. Braiding geometry contributes up to $20 \mathrm{~dB}$ improvement in the shielding effectiveness of cables. The actual figure is highly dependent upon weaving geometry, i.e., tighter weaves offer larger values of shielding effectiveness.

4. Double-braided shielding exhibits the largest improvement in shielding effectiveness seen in this study. The improvement can be as much as $30 \mathrm{~dB}$ but is nominally 10 to $20 \mathrm{~dB}$ for the cables that were tested for this report.

5. EMP-hardened connectors can provide up to $50 \mathrm{~dB}$ of shielding effectiveness if the total connector assembly is properly constructed. This implies that the shield braid has to be intact 
at the connector shell to avoid possible leakage and resonance effects caused by the connector hardware.

Additional effort should be made on connector hardware and closure technologies. An investigation on the improvements to be gainea by use of completely soldered shield bra'd to back-shell conflgurations should be included as part of the study.

Another area for continued work should involve the Investigation of cables which are unshielded but contain pairs or multiple conductors which are shielded by either braid or foll covering.

This report has presented a measurement setup for the determination of the shielding effectiveness of assorted wires, cables, and connectors. The described hardware permits quick changes between component classes and provides a stable, repeatable measurement. The setup is directly applicable to susceptiblitty evaluation, component acceptance testing, and quality control efforts. 


\section{REFERENCES}

[1] Military Standard, MIL-STD-1344A, Method 3008, "Test Methods for Electrical Connectors,"U. S. Department of Defense, Sept. 1980.

[2] M. T. Ma, M. Kanda, M. L. Crawford and E. B. Larsen, "A Review of Electromagnetic Compatibility/Interference Measurement Methodologies," Proceedings of the IEEE, Vol. 73; No. 3, March 1985.

[3] M. L. Crawford and J. M. Ladbury, "Mode-Stirred Chamber for Measuring Shielding Effectiveness of Cables and Connectors. An Assessment of MIL-STD-1344A Method 3008," Proc. of IEEE; 1988 International Symposium on Electromagnetic Compatibilty, Seattle, WA., Aug 2-4, 1988.

[4] BREEZE tubing- brand of corrugated sleeving, manufactured by: BREEZE ILLINOIS

Main \& Agaro Sts. Wyoming, IL 61491

[5] D. R. Smith, "Measurement of the Shielding Effectiveness of Shielded, Multiconductor Cables at Microwave Frequencies Using a Mode-Tuned Reverberation Chamber," Technical Report, Kaman Sciences Corp., Colorado Springs, CO., October 1.987.

[6] Space Cloth, Eccosorb SC-377, woven fabric microwave absorber, Emerson \& Cumming, W. R. Grace \& Co., Canton, MA 02021.

[7] Edward F. Vance, "Coupling to Shielded Cables," John Wiley and Sons, New York, NY, 1978. 

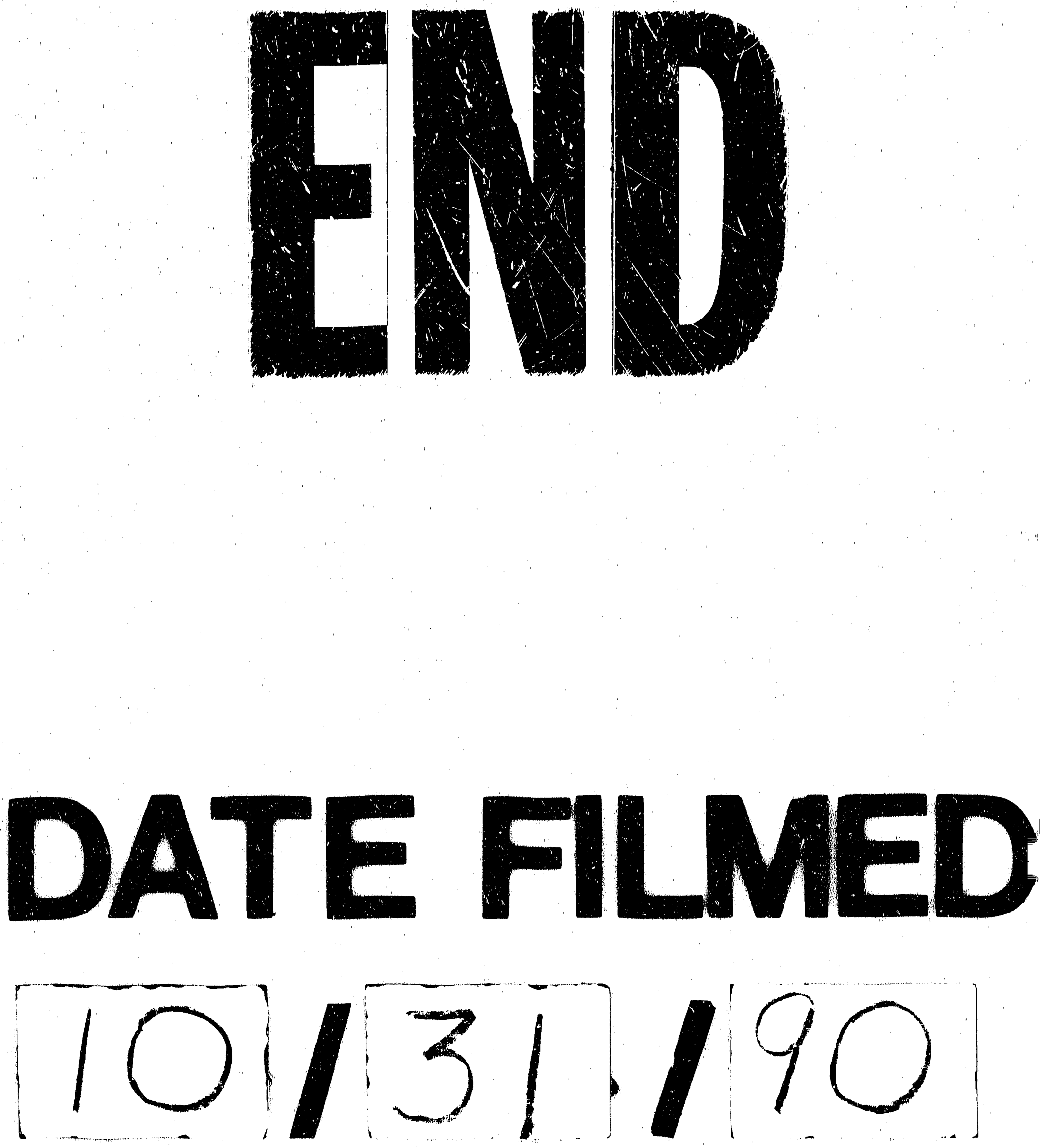
